\title{
BIM 4D aplicado à gestão logística: implementação na montagem de sistemas pré- fabricados de concreto engineer-to-order
}

\author{
4D BIM applied to logistics management: implementation \\ in the assembly of Engineer-to-order prefabricated \\ concrete systems
}

\section{Fernanda Saidelles Bataglin \\ Daniela Dietz Viana \\ Carlos Torres Formoso lamara Rossi Bulhões}

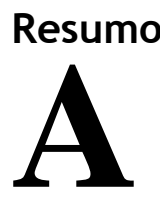

Resumo

incerteza tende a ser alto. A literatura sugere o uso de Building Information Modeling (BIM) para facilitar o compartilhamento de informações e apoiar a tomada de decisões, assim como a aplicação de conceitos e princípios da Produção Enxuta. Particularmente em relação ao processo de montagem, o BIM 4D pode ser utilizado para simular algumas operações, apoiando o planejamento e controle da produção. O presente artigo propõe um conjunto de diretrizes para a utilização do BIM 4D e conceitos e princípios da Produção Enxuta para apoiar a gestão logística do processo de montagem de sistemas pré-fabricados em concreto do tipo engineer-to-order. Foi adotada a abordagem metodológica da Design Science Research, tendo por base um estudo empírico realizado em uma empresa que fornece estruturas pré-fabricadas de concreto. As principais contribuições do trabalho referem-se o uso de BIM 4D para padronizar as operações logísticas e para a gestão de informações relacionadas ao status do sistema.

Palavras-chave: Gestão logística. BIM 4D. Produção enxuta. Pré-fabricação. Engineer-to-order.

Fernanda Saidelles Bataglin Universidade Federal do Rio Grande Porto Alegre - RS - Brasil

Daniela Dietz Viana Universidade Federal do Rio Grande do Sul Tramandaí - RS - Brasil

Carlos Torres Formoso Universidade Federal do Rio Grande Porto Alegre - RS - Brasil

lamara Rossi Bulhões Universidade Federal do Rio Grande do Sul Tramandaí - RS - Brasil

Recebido em 14/06/17 Aceito em 13/09/17

\section{Abstract}

The management of prefabricated building systems demands an intense exchange of information between the the plant and the construction site, in order to synchronize the production of components, logistic operations and site assembly, especially in engineer-to-order environments, in which the degree of uncertainty tends to be high. The literature suggests the use of Building Information Modeling (BIM) to facilitate the sharing of information and to support decision-making in this type of environment, as well as the application of Lean Production concepts and principles. Particularly in relation to the assembly process, $4 D$ BIM can be used to simulate some operations, supporting production planning and control. This paper proposes a set of guidelines for using 4D BIM and Lean Production concepts and principles to support logistics management for the assembly process in engineer-to-order concrete prefabricated systems. Design Science Research was the methodological approach adopted in this investigation, which was based on an empirical study carried out in a company that delivers prefabricated concrete structures. The main contributions of this study are related to the use of BIM 4D for standardizing logistics operations, and for managing information related to system status

Keywords: Logistic management. 4D BIM. Lean production. Prefabrication. Engineer-toorder.

BATAGLIN, F. S.; VIANA, D. D.; FORMOSO, C. T.; BULHÕES, I. R. BIM 4D aplicado à gestão logística: implementação na 173 montagem de sistemas pré-fabricados de concreto Engineer-to-order. Ambiente Construído, Porto Alegre, v. 18, n. 1, p. 173-192, jan./mar. 2018. 


\section{Introdução}

A literatura aponta diversas vantagens no uso de sistemas construtivos pré-fabricados quando comparados a métodos tradicionais de construção, tais como a redução dos custos totais, a redução do tempo de execução, a melhoria da qualidade, a redução de perdas na produção e a eliminação de riscos de acidentes (DEFFENSE; CACHADINHA, 2011; ZHAI; ZHONG; HUANG, 2015).

Segundo Koskela (2003), a industrialização da construção pode ser vista como um meio para a redução da parcela de atividades de construção nos canteiros de obras, com a transferência do trabalho para as fábricas, de modo a serem realizadas em um ambiente mais controlado (BALLARD; HOWELL, 1998a). No entanto, essa transferência de atividades resulta em demandas por melhorias na gestão da cadeia de suprimentos e de atividades logísticas (LESSING; STEHN; EKHOLM, 2005). Com a industrialização, o processo de construção tende a tornar-se mais complexo e vulnerável a partir da necessidade de dois locais de produção (fábrica e canteiro de obras), e, com isso, existe maior necessidade de coordenação (KOSKELA, 1992).

Uma elevada parcela das empresas de construção industrializada possui sistemas de produção do tipo Engineer-to-order (ETO) em função da necessidade de rápidas respostas às demandas dos clientes (MCGOVERN; HICKS; EARL, 1999). Nesses sistemas, os produtos são produzidos especificamente para atender às necessidades do cliente, e alguns componentes podem ser customizados e produzidos em baixo volume (POWELL et al., 2014). Matt, Dallasega e Rauch (2015) ressaltam que os processos de fabricação e montagem em empresas ETO muitas vezes são desconectados em função da falta de confiabilidade do planejamento no canteiro de obras e da comunicação insuficiente entre os responsáveis pela fabricação e pela montagem. De fato, Tommelein (1998) aponta que as equipes de montagem de sistemas pré-fabricados com frequência enfrentam o chamado "problema de correspondência", ou seja, elas dispendem tempo para encontrar os recursos disponíveis e garantir que o elemento correto seja instalado no lugar previsto.

Skjelbred, Fossheim e Drevland (2015) enfatizam que as decisões logísticas, tais como o planejamento do leiaute do canteiro e a alocação de recursos adequados, são essenciais para a eficiência de sistemas pré-fabricados. Tais sistemas podem resultar em economia de espaço para armazenamento de materiais, melhorias no controle da qualidade da produção das peças, redução das perdas (ČUŠ-BABIČ et al., 2014), assim como aumento da eficiência e rapidez do processo de montagem (PHENG; CHUAN, 2001). No entanto, as economias de tempo decorrentes de uma instalação mais rápida podem ser perdidas se os processos logísticos não forem devidamente planejados e controlados (PHENG; CHUAN, 2001).

O alinhamento do tamanho, sequência e frequência dos lotes de fabricação de peças, de transporte e de montagem são questões críticas para os sistemas construtivos do tipo ETO (MATT; DALLASEGA; RAUCH, 2015). Assim, a cooperação e o compartilhamento de informações entre a fábrica e o canteiro de obras são importantes para a eficácia do planejamento e controle da produção e para a gestão logística (CHAN; ZENG, 2004). Nesse contexto, existe grande potencial para aplicação de conceitos e princípios da filosofia da Produção Enxuta (Lean Production).

Para Lessing, Stehn e Ekholm (2005), os processos industrializados requerem informações precisas e confiáveis, e as tecnologias da informação e comunicação emergentes podem contribuir para realizar de forma eficaz as alterações e atualizações de materiais digitais e para efetuar trocas e armazenamento de dados (LESSING; STEHN; EKHOLM, 2005). O Building Information Modeling (BIM) pode ser visto como uma abordagem orientada pela tecnologia (PAPADONIKOLAKI; VRIJHOEF; WAMELINK, 2015) que tem como característica principal facilitar o compartilhamento e o reúso das informações durante todo o ciclo de vida do empreendimento (LEE; YU; JEONG, 2013). Eastman et al. (2011) salientam que as empresas do tipo ETO, em função da complexidade de seus processos e da singularidade de seus produtos (MATT; DALLASEGA; RAUCH, 2014), potencialmente estão entre as maiores beneficiárias de BIM, uma vez que seus componentes demandam projetos de engenharia em prazos relativamente curtos e colaboração intensa entre os intervenientes.

A adoção de sistemas pré-fabricados ETO para a construção de um empreendimento implica a necessidade de sincronia entre os distintos ambientes de produção (fábrica e obra) e a necessidade de uma gestão logística mais eficaz com trocas de informações mais confiáveis. Diante disso, o BIM, em especial a modelagem 4D (em quatro dimensões), por seu processo iterativo de geração, análise e compartilhamento de informações, pode servir como uma plataforma para a integração de diferentes aspectos da informação da construção (HARRIS; ALVES, 2013). A partir da visualização dos planos gerados por meio de modelos $4 \mathrm{D}$, pode-se avaliá-los e revisá-los com 
mais facilidade, resultando na elaboração de planos mais confiáveis (EASTMAN et al., 2011) a partir da identificação de possíveis problemas na fase de construção, ainda na fase de projeto (HEESOM; MAHDJOUBI, 2004).

O presente artigo propõe um conjunto de diretrizes para a utilização do BIM 4D e conceitos e princípios da Produção Enxuta para apoiar a gestão logística do processo de montagem de sistemas construtivos pré-fabricados em concreto do tipo ETO, amplamente utilizados no Brasil. São apresentados os resultados obtidos em um estudo desenvolvido em colaboração com uma empresa, a qual fornece soluções completas de estruturas pré-fabricadas em concreto para empreendimentos altamente customizados, que podem ser consideradas do tipo ETO.

\section{Referencial teórico}

\section{Estudos anteriores sobre o uso de BIM 4D na gestão da produção}

Borjeghaleh e Sardroud (2016) apontam os potenciais benefícios da aplicação do BIM na gestão de sistemas industrializados, destacando o uso da modelagem BIM 4D para o planejamento do fluxo de materiais, mão de obra e equipamentos em diferentes etapas do processo. Ergen e Akinci (2008), por sua vez, destacam o papel da tecnologia da informação e comunicação na gestão do fluxo de informações em sistemas de produção do tipo ETO. Estes autores afirmam que, devido à necessidade de customização, é necessário rastrear cada peça individualmente, de forma a permitir a troca de informações entre as etapas de produção de peças pré-fabricadas, expedição e montagem. A transparência entre os processos de fabricação e de montagem torna o planejamento de curto prazo mais preciso, resultando na redução de prazos e na menor exigência de estoques de componentes (ČUŠ-BABIČ et al., 2014).

Diversas pesquisas têm sido desenvolvidas utilizando BIM 4D e apontando seus benefícios no âmbito da gestão da produção. Kassem, Dawood e Chavada (2015) propuseram um método para a gestão dos espaços de trabalho do canteiro de obras com o propósito de evitar congestionamentos e conflitos espaciais e, como consequência, de reduzir os impactos negativos no tempo e segurança do projeto. Com o mesmo propósito, Choi et al. (2014) sugeriram uma estrutura para o processo de planejamento do espaço de trabalho em um ambiente BIM 4D integrado ao plano da construção, evitando problemas como retrabalhos e redução da produtividade. Biotto, Formoso e Isatto (2015) desenvolveram um método para apoiar a gestão de sistemas de produção em empreendimentos de construção com uso da modelagem BIM 4D para o projeto do sistema de produção e planejamento da produção, salientando os benefícios do BIM 4D como o aumento da comunicação e o entendimento das decisões entre os participantes, e o entendimento das inter-relações entre as decisões da gestão da produção. Yu, Li e Luo (2016) desenvolveram um modelo dinâmico baseado em BIM para o fornecimento de materiais no canteiro de obras com o objetivo de integrar as informações de quantidade de materiais, tempo de entrega e áreas disponíveis para armazenamento no canteiro de obras, auxiliando no arranjo dos materiais no canteiro e na melhoria da eficiência da produção.

O uso associado do BIM 4D a dispositivos visuais no planejamento e controle da construção também é um tema bastante explorado e trouxe contribuições relevantes para o presente trabalho. Pitake e Patil (2013) sugerem que o benefício mais significativo da modelagem é a melhoria na visualização do progresso dos trabalhos da construção, resultando em uma economia de $11 \%$ do tempo total de construção e de $4 \%$ nos custos do empreendimento. Brito e Ferreira (2015) sugeriram estratégias para representação e análises da modelagem 4D na gestão da produção, e a modelagem 4D com diferenciação de cores para as diferentes atividades, em grau de importância e aplicabilidade, teve uma média superior em relação à representação de atividades por uma única cor. Zhang e Li (2010) integraram o BIM 4D, tecnologias da construção virtual e representação visual com o objetivo de melhorar os planos da construção e o leiaute do canteiro de obras. Li, Stephens e Ryba (2014) descreveram a implementação da modelagem 4D em um empreendimento que, com as ferramentas de visualização, permitiram o estudo dos fluxos de trabalho, além do planejamento e controle da utilização dos espaços.

\section{Gestão logística e a aplicação de conceitos e princípios da Produção Enxuta}

No contexto da construção civil, a gestão logística compreende planejamento, organização, coordenação e controle do fluxo de materiais a partir da extração de matéria-prima até a incorporação deles no produto final (CLAUSEN, $1995^{1}$ apud AGAPIOU et al., 1998). Silva e Cardoso (1998) propõem a divisão das funções da

${ }^{1}$ CLAUSEN, L. E. Building Logistics. Copenhagen: Danish Building Research Institute, 1995. Report No. 256. 
logística em empresas da construção em duas abordagens principais: logística de suprimentos e logística do canteiro de obras.

A logística de suprimentos está relacionada ao fornecimento de materiais, equipamentos e recursos humanos necessários para a produção do empreendimento, enquanto a logística do canteiro de obras refere-se à gestão dos fluxos físicos e dos fluxos de informações associados à execução das atividades no canteiro de obras (SERRA; OLIVEIRA, 2003). À medida que a construção do empreendimento avança, as atividades mudam e, consequentemente, os objetos de apoio associados a essas atividades também estão sujeitos a mudanças. Diante disso, o planejamento do leiaute do canteiro de obras é crucial para a gestão logística do canteiro de obras, pois pode contribuir para reduzir o tempo de transporte e ter um impacto positivo na produtividade e nas condições de trabalho (PAPADAKI; CHASSIAKOS, 2016).

Embora diversos trabalhos relevantes sobre a modelagem BIM 4D na gestão da produção tenham sido desenvolvidos, poucos abordaram a gestão logística dos processos de montagem, incluindo a logística de suprimentos de materiais integrada à logística do canteiro de obras em sistemas préfabricados. A maioria dos trabalhos desenvolvidos, conforme descrito acima, tem foco na logística do canteiro de obras, atuando na elaboração de leiaute que atenda às exigências para um fluxo de trabalho sem interrupções, sendo voltados, principalmente, a canteiros de obras com sistemas construtivos convencionais, e não sistemas pré-fabricados em concreto.

Um dos poucos trabalhos que abordaram a gestão logística de sistemas construtivos pré-fabricados do tipo ETO foi o de Bortolini (2015), que propôs um modelo de planejamento e controle logístico de estruturas metálicas pré-fabricadas com o uso da modelagem BIM 4D. Foi explorado nele a sinergia entre funcionalidades do BIM e princípios da filosofia da Produção Enxuta (Lean Production), conforme sugerido por Sacks et al. (2010). Bortolini (2015) propôs um modelo hierarquizado de planejamento e controle logístico com o uso de BIM 4D que busca introduzir a produção puxada, padronizar processos logísticos, dividir a obra em pequenos lotes e aumentar a transparência de processos. Esse modelo dá ênfase à gestão dos fluxos físicos, incluindo equipamentos e materiais, considerando operações de descarregamento e movimentação dos componentes e a posição dos estoques.

De fato, sistemas de produção ETO requerem ciclos curtos de aprendizagem, o que os torna mais adaptáveis às mudanças (JOHNSTON;
BRENNAN, 1996). Nesse sentido, a criação de mecanismos para a produção puxada permite a criação de um sistema de planejamento e controle que responde às constantes mudanças do ambiente. Produção puxada, nesse contexto, tem um significado mais amplo: considerar o status do sistema antes de se iniciar a produção, de forma a avaliar e limitar a quantidade de trabalho em progresso existente (HOPP; SPEARMAN, 2000). Para isso é necessário que se estabeleçam diferentes níveis de planejamento e que as informações sejam gradualmente detalhadas a partir de informações obtidas sobre o status do sistema, de forma similar ao que é realizado no sistema Last Planner (BALLARD; HOWELL, 1998b).

Hopp e Spearman (2004) salientam que a simples limitação do trabalho em progresso não é condição suficiente para melhorar o sistema e que deve haver um esforço continuado para que esse nível seja continuamente reduzido. Os mesmos autores apontam que essa prática está relacionada ao esforço de redução do tamanho do lote, principalmente no que se refere ao lote de transferência entre diferentes equipes. A redução do tamanho do lote colabora com a redução do tempo de ciclo das atividades e permite que as equipes se beneficiem da aprendizagem que obtiveram na produção do lote anterior (KOSKELA, 1992).

\section{Método de pesquisa}

\section{Abordagem metodológica}

A pesquisa está posicionada como Design Science Research, também conhecida como pesquisa construtiva. Esse tipo de pesquisa busca explorar novas soluções para resolver problemas, além de explicar a exploração deles, melhorando o processo de solução de problemas estabelecidos (HOLMSTROM; KETOKIVI; HAMERI, 2009). A Design Science Research tem foco no desenvolvimento de conhecimento traduzido na prescrição de alternativas de soluções para uma classe de problemas (VAN AKEN, 2004).

Como estratégia de pesquisa, utilizou-se a pesquisaação, por ser essa uma das estratégias que permitem a participação ativa do pesquisador no fenômeno observado (THIOLLENT, 2005). Thiollent (2005) define pesquisa-ação como um tipo específico de pesquisa com base empírica, que é concebida e realizada por meio de uma ação em que os pesquisadores e algumas pessoas participantes da situação ou do problema estão envolvidos de modo cooperativo.

A realização da pesquisa-ação é justificada pela necessidade de realizar intervenções em uma organização para propor as diretrizes para aplicação 
do BIM 4D. Esse processo foi desenvolvido e consolidado a partir da intervenção do pesquisador mediante ciclos de aprendizagem, em que a pesquisa se alterna em planejamento, ação, avaliação e reflexão (SUSMAN; EVERED, 1978). Esse tipo de pesquisa-ação alinha-se ao caráter prescritivo da Design Science Research, uma vez que é gerado conhecimento prescritivo, sintetizado em um conjunto de diretrizes, por meio da cooperação entre a equipe de pesquisadores e a empresa-alvo envolvida. Cabe salientar que este estudo faz parte de um projeto mais amplo, cujo objetivo principal foi propor um modelo para gestão dos processos logísticos envolvidos na montagem de sistemas pré-fabricados do tipo Engineer-toorder, com uso de BIM 4D (BATAGLIN, 2017).

A empresa envolvida no estudo empírico, denominada neste artigo de Empresa A, atua no segmento de mercado de estruturas pré-fabricadas em concreto, com quatro fábricas em operação. A empresa fabrica, projeta e monta estruturas préfabricadas do tipo ETO, as quais contêm peças específicas e únicas para cada empreendimento. Sua atuação é diversificada em termos de segmentos de mercado, incluindo shoppings centers, varejo (supermercados e lojas), galpões, prédios verticais, entre outros. A escolha da empresa deu-se por seu interesse em participar da pesquisa e pelo fato de que ela estava iniciando um programa de melhorias em seu sistema de produção com base na filosofia da Produção Enxuta.

\section{Delineamento da pesquisa}

Na Figura 1 é apresentado o delineamento da pesquisa, que foi dividido em três etapas:

(a) compreensão;

(b) desenvolvimento; $\mathrm{e}$

(c) análise e reflexão.

O estudo teve duração de onze meses. A etapa de compreensão durou três meses, e os outros oito meses foram dedicados às etapas de desenvolvimento e análise e reflexão, que tiveram sobreposição em função do tipo de estratégia de pesquisa adotada.

A primeira etapa da pesquisa consistiu na identificação de uma lacuna do conhecimento a partir da análise profunda de problema prático, conforme sugerido por Van Aken (2004). Foram utilizados dados de estudos anteriores sobre sistemas pré-fabricados do tipo ETO (BORTOLINI, 2015; VIANA, 2015; TREVISAN,

20 nível de desenvolvimento (Level of development - LOD) de um modelo BIM 3D refere-se ao grau de detalhamento com que a
2016) e também informações coletadas diretamente na Empresa A. Essa etapa permitiu à equipe da pesquisa compreender o contexto e as necessidades de melhoria da empresa. Com relação ao processo logístico da empresa, foi feito um diagnóstico para entender as formas de abastecimento à obra e a troca de informações entre a fábrica e as obras, bem como os métodos de planejamento e controle utilizados na montagem, incluindo os processos logísticos.

Ainda durante a etapa de compreensão, foi realizada a modelagem $3 \mathrm{D}$ do projeto do empreendimento estudado e do canteiro de obras, sendo adotado o software Autodesk Revit. Para a modelagem 3D desenvolvida pelos pesquisadores o nível de desenvolvimento utilizado para o modelo foi LOD ${ }^{2}$ 300 para os elementos da estrutura pré-fabricada de concreto e LOD 200 para a modelagem do canteiro de obras e entornos. Foi também selecionado o software para modelagem 4D denominado Synchro PRO, e realizado treinamento para a utilização desse software por meio de tutoriais e vídeos disponíveis no website ${ }^{3}$ do fabricante.

A Figura 2 representa a interface do programa Synchro PRO com uma visão geral do modelo desenvolvido. No modelo 4D foram inseridos dados de montagem referentes ao vínculo entre cada componente do modelo 3D a uma atividade do plano de longo prazo. Com isso, foi possível cruzar as informações semânticas do modelo, tais como nome das peças, conforme a localização ou lote de produção, com informações gráficas do leiaute do canteiro de obras, tais como acessos, possíveis áreas de descarregamento e estoques.

O diagnóstico apontou que o planejamento e controle da montagem e a gestão logística eram ineficazes e que falhas no fluxo de informações entre a fábrica e a obra traziam prejuízos ao processo de montagem. Como resultado, os problemas práticos a seguir foram identificados e contribuíram para definir o escopo da pesquisa:

(a) o foco dos gestores do processo de montagem era maximizar a utilização da capacidade da equipe de montagem. Embora a divisão da obra em etapas adotada pela Empresa A facilitasse o controle de peças para montagem, a divisão ainda era em grandes lotes, resultando na falta de flexibilidade para enfrentar alguns desafios apresentados, tais como incertezas ou alterações no projeto por parte do cliente e mudanças da sequência de montagem devido a problemas na produção ou a pedido da empresa construtora. Diante disso, não era possível definir uma

geometria e as demais informações dos objetos foram produzidas (BIMFORUM, 2016).

${ }^{3}$ Disponível em: <https://synchroltd.com/training/>. 
sequência de montagem muito tempo antes da execução de cada etapa;

(b) o processo de planejamento e controle do processo de montagem não era sistemático, o que contribuía para a ineficácia na troca de informações entre fábrica e obra. Como resultado, o fluxo de trabalho das equipes era dificultado em função de atrasos na entrega dos componentes necessários para a realização da montagem. Muitas vezes eram recebidas cargas com peças desnecessárias, resultando em grandes áreas de estoque e restringindo a área necessária para acesso e trânsito de equipamentos e movimentação de pessoas; e

(c) havia necessidade de mudança no processo de projetos da Empresa $\mathrm{A}$ devido à exigência de alguns clientes para a adoção do BIM em seus projetos.

\section{Figura 1 - Delineamento do processo de pesquisa}

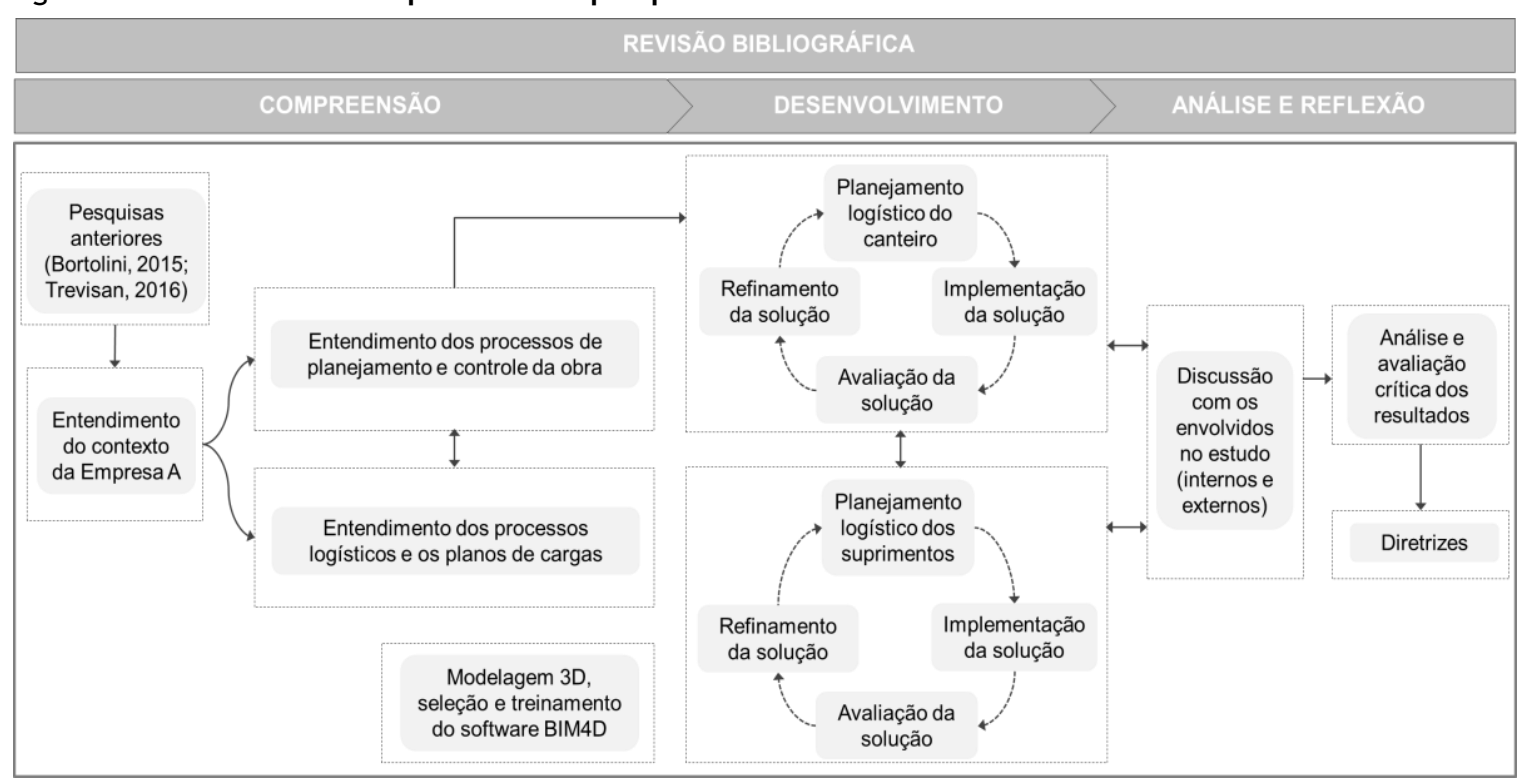

Figura 2 - Interface do software de modelagem 4D

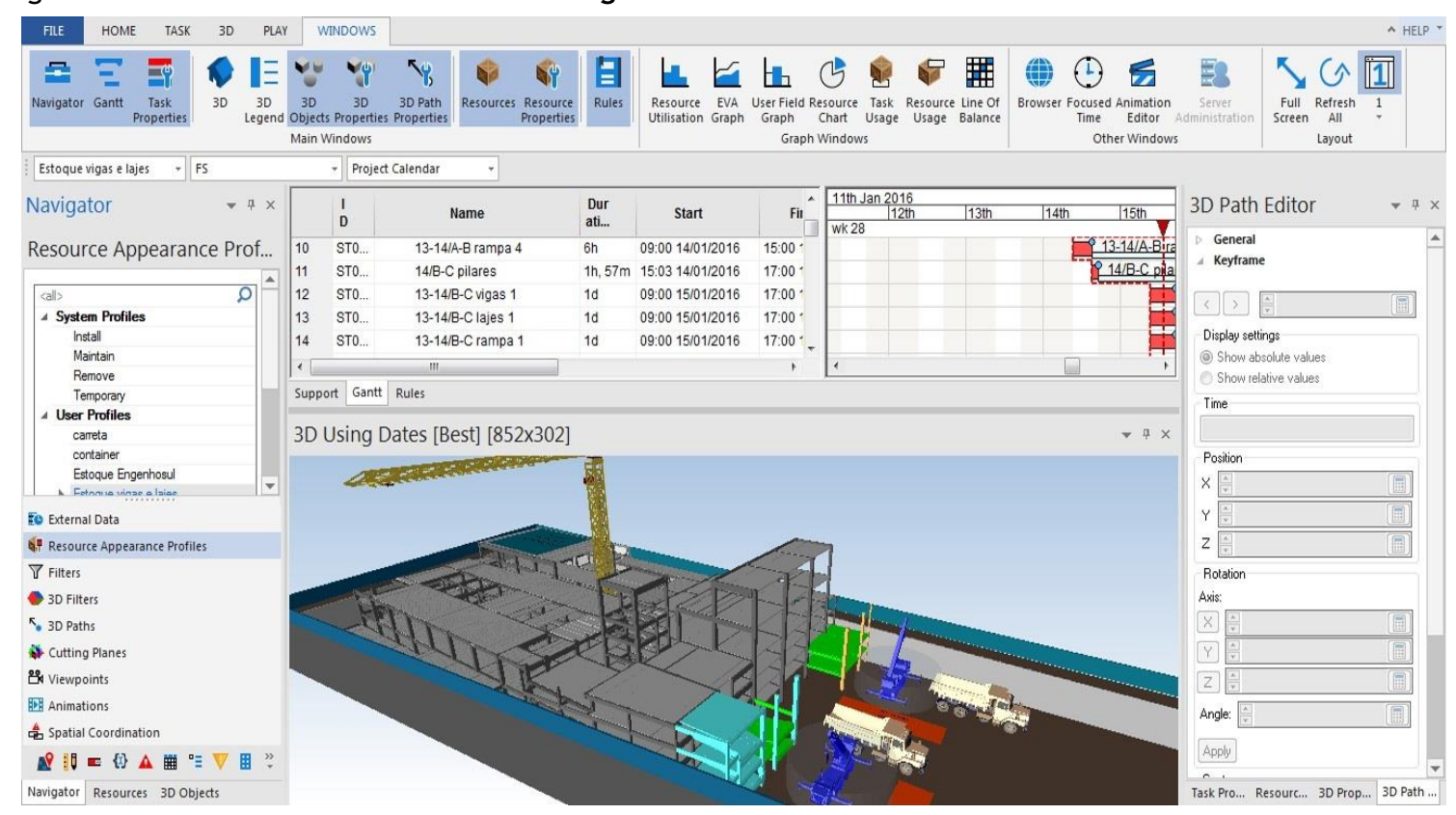


$\mathrm{Na}$ etapa de desenvolvimento os modelos BIM 4D apoiaram à tomada de decisões relacionadas ao planejamento logístico do canteiro de obras, com ênfase na organização do canteiro de obras e no planejamento do fluxo de componentes, incluindo a definição e o sequenciamento das cargas. Durante esta etapa foram realizados workshops para discussão dos resultados com diversos representantes da empresa, que marcaram o fechamento de ciclos de aprendizagem.

$\mathrm{Na}$ etapa de análise e reflexão foram realizadas discussões entre a equipe de pesquisadores e os usuários das ferramentas propostas a fim de refletir sobre o processo de implementação e os resultados alcançados no trabalho. Como resultado da etapa, foi elaborado um conjunto de diretrizes para auxiliar empresas na implementação do BIM 4D para apoiar a gestão logística de obras em sistemas pré-fabricados em concreto do tipo ETO.

\section{Descrição do empreendimento}

O empreendimento estudado tinha área construída de cerca de $55.000 \mathrm{~m}^{2}$ e era localizado em Porto Alegre, RS. A estrutura de concreto armado era mista, sendo $67 \%$ da área correspondente à estrutura pré-fabricada de concreto e $33 \%$ correspondente a uma torre construída em estrutura moldada in loco. Neste empreendimento a empresa foi contratada para a execução da estrutura de concreto pré-fabricada, e as fábricas responsáveis pelo abastecimento desse empreendimento eram distantes, situadas nos estados de Santa Catarina e Paraná.

A área da estrutura da edificação foi dividida em três lotes, denominados de setores (ver Figura 3), que possibilitaram a segmentação dos prazos de execução e o controle de datas-marcos.

$\mathrm{O}$ canteiro de obras era restrito quanto a espaços e acessos, principalmente pela necessidade de uma grande escavação para a construção de subsolos. Havia apenas uma entrada de veículos, e o acesso de veículos ao canteiro de obras ocorria por meio de uma rampa relativamente estreita (Figura 4). Além disso, diferentes equipes estavam executando atividades distintas e interdependentes ao mesmo tempo. A montagem dos pilares dependia da execução dos blocos de fundação, que apresentavam um ritmo mais lento de produção e eram de responsabilidade de outra empresa. Em função de atrasos e mudanças na sequência de execução das fundações, a montagem da estrutura foi prejudicada pela falta de frentes de trabalho.

Figura 3 - Representação esquemática da divisão dos setores da edificação

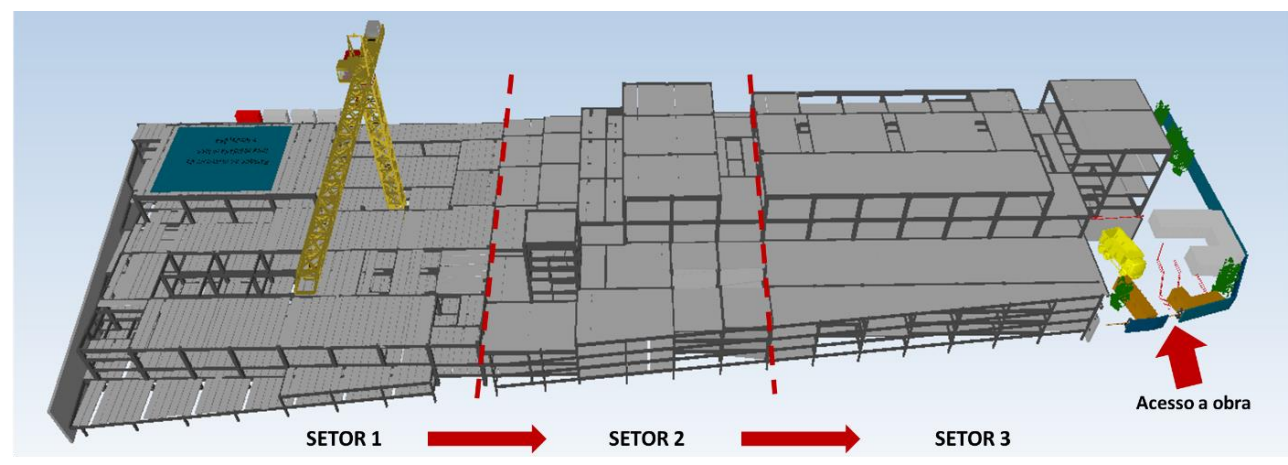

Figura 4 - Visão geral do canteiro de obras

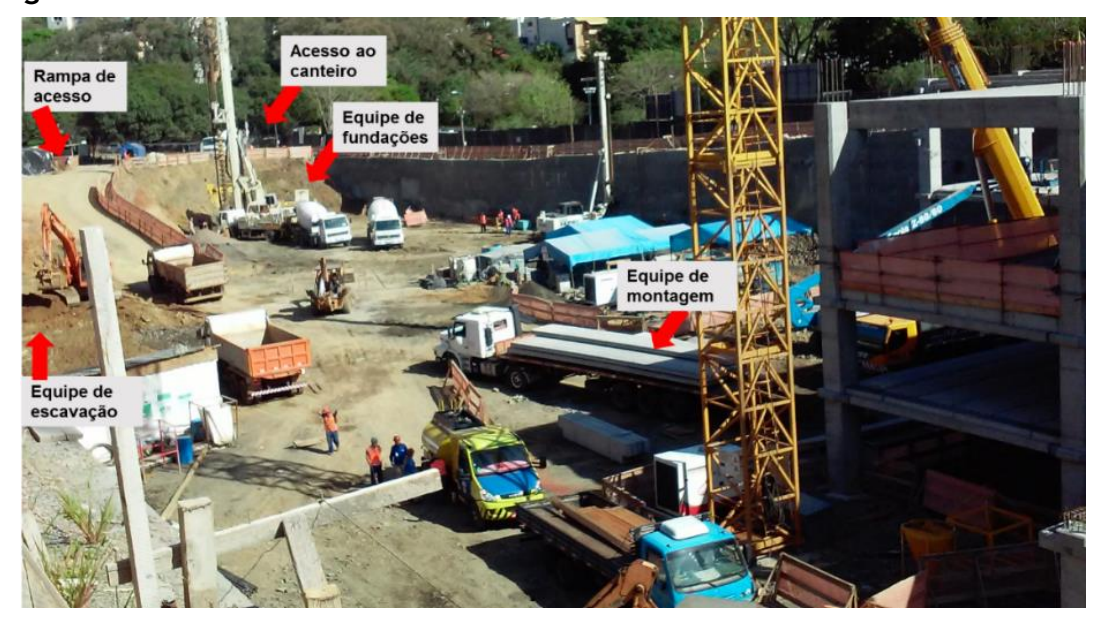


Métodos e técnicas de coleta de dados

O estudo foi dividido em três etapas principais: etapa de compreensão; etapa de desenvolvimento; e etapa de análise e reflexão. No Quadro 1 são apresentadas as fontes de evidências utilizadas em cada uma delas, assim como seus objetivos delas para as ações desenvolvidas ao longo do estudo.

Quadro 1 - Fontes de evidências adotadas na pesquisa

\begin{tabular}{|c|c|c|c|c|}
\hline & Ações & $\begin{array}{l}\text { Fontes de } \\
\text { Evidências }\end{array}$ & Objetivo & \\
\hline \multirow{3}{*}{ 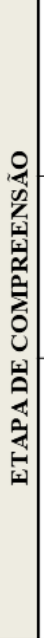 } & $\begin{array}{l}\text { Visitas ao } \\
\text { canteiro de } \\
\text { obras }\end{array}$ & $\begin{array}{l}\text { Observação } \\
\text { direta } \\
\text { Registros } \\
\text { fotográficos }\end{array}$ & $\begin{array}{l}\text { Foram realizadas } 5 \text { visitas ao canteiro de obras com o objetivo de: } \\
\text { - Coletar informações sobre o planejamento e controle dos processos de } \\
\text { montagem; } \\
\text { - Compreender o fluxo de informações entre a fábrica e a obra; } \\
\text { - Entender o processo de planejamento do leiaute do canteiro de obras. }\end{array}$ & \\
\hline & $\begin{array}{l}\text { Reuniões de } \\
\text { planejamento } \\
\text { de curto } \\
\text { prazo }\end{array}$ & $\begin{array}{l}\text { Observação } \\
\text { participante } \\
\text { Análise de } \\
\text { documentos }\end{array}$ & $\begin{array}{l}\text { Foram realizadas } 4 \text { reuniões com duração de aproximadamente } 1 \text { hora } \\
\text { envolvendo representantes da equipe de obra da Empresa A (engenheiro gestor } \\
\text { da obra) e da equipe da empresa construtora da obra (engenheiros responsáveis } \\
\text { pelo planejamento e pela execução), nas quais a modelagem } 4 \mathrm{D} \text { foi utilizada } \\
\text { para apoio à tomadas de decisões quanto a logística do canteiro de obras. }\end{array}$ & \\
\hline & Workshop & $\begin{array}{l}\text { Observação } \\
\text { participante }\end{array}$ & $\begin{array}{l}\text { No } 1^{\circ} \text { workshop }(28 / 08 / 2015) \text { participaram, além da equipe de pesquisadores, } \\
\text { os representantes do departamento de planejamento integrado e do } \\
\text { departamento de planejamento e controle da produção, o Gerente de obras da } \\
\text { região Sul, o Engenheiro e o estagiário da obra. Neste workshop foi } \\
\text { apresentada a aplicação do BIM } 4 \mathrm{D} \text { que estava sendo utilizada nas reuniões de } \\
\text { planejamento. Também discutiu-se a complexidade da obra, que estava no seu } \\
\text { estágio inicial, e as dificuldades enfrentadas pela Empresa A em atender a } \\
\text { demanda do cliente. }\end{array}$ & \\
\hline \multirow{4}{*}{ 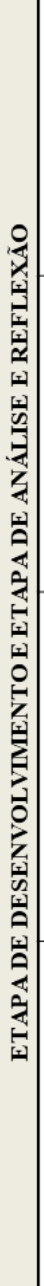 } & $\begin{array}{l}\text { Visitas ao } \\
\text { canteiro de } \\
\text { obras }\end{array}$ & $\begin{array}{l}\text { Observação } \\
\text { direta } \\
\text { Registros } \\
\text { fotográficos }\end{array}$ & $\begin{array}{l}\text { Foram realizadas } 21 \text { visitas ao canteiro de obras com o objetivo de: } \\
\text { - Coletar informações sobre leiaute do canteiro, posicionamentos dos } \\
\text { equipamentos de montagem, número de equipes e atividades em } \\
\text { andamento, para posterior comparação ao planejado; } \\
\text { - Analisar as necessidades de melhorias com base nas conversas informais } \\
\text { com os envolvidos no processo de montagem; } \\
\text { - Observar a implementação dos planos logísticos, incluindo o planejamento } \\
\text { das cargas. }\end{array}$ & \\
\hline & $\begin{array}{l}\text { Visitas à } \\
\text { fábrica de } \\
\text { Curitiba/PR }\end{array}$ & $\begin{array}{l}\text { Observação } \\
\text { direta } \\
\text { Entrevistas } \\
\text { não } \\
\text { estruturadas }\end{array}$ & $\begin{array}{l}\text { Foram realizadas } 2 \text { visitas à fábrica em Curitiba/PR, que tiveram como } \\
\text { objetivo: } \\
\text { - Ampliar o entendimento sobre os processos de produção das peças; } \\
\text { - Compreender a interação entre os departamentos da empresa e também a } \\
\text { relação entre a Empresa A e seus respectivos clientes a partir da percepção } \\
\text { dos entrevistados. Foram realizadas } 6 \text { entrevistas não estruturadas, com } \\
\text { duração de aproximadamente } 1 \text { hora, com os responsáveis pelos } \\
\text { departamentos de projetos, planejamento integrado, planejamento e } \\
\text { controle da produção, controle de qualidade, expedição e montagem. }\end{array}$ & 동 \\
\hline & $\begin{array}{l}\text { Reuniões de } \\
\text { planejamento } \\
\text { de curto } \\
\text { prazo }\end{array}$ & $\begin{array}{l}\text { Observação } \\
\text { participante }\end{array}$ & $\begin{array}{l}\text { Foi realizada } 1 \text { reunião com duração de aproximadamente } 1 \text { hora envolvendo } \\
\text { representantes da equipe de obra da Empresa A (engenheiro gestor da obra), e } \\
\text { da equipe da empresa construtora da obra (engenheiros responsáveis pelo } \\
\text { planejamento e pela execução), na qual a modelagem } 4 \mathrm{D} \text { foi utilizada para } \\
\text { apoio à tomadas de decisões quanto a logística do canteiro de obras. } \\
\text { Foram realizadas } 18 \text { reuniões entre a equipe de pesquisadores e integrantes da } \\
\text { Empresa A (engenheiro e estagiário) para discutir o plano de curto prazo e o } \\
\text { planejamento das cargas, com apoio dos modelos } 4 \mathrm{D} \text { para entendimento da } \\
\text { sequência de montagem e melhorias nos processos e, analisar os dados de PPC } \\
\text { registrados. }\end{array}$ & \\
\hline & Workshops & $\begin{array}{l}\text { Observação } \\
\text { participante }\end{array}$ & $\begin{array}{l}\text { No } 2^{\circ} \text { workshop }(23 / 10 / 2015) \text { participaram, além dos participantes do } 1^{\circ} \\
\text { workshop, o Presidente da empresa, o Coordenador de projetos, o Coordenador } \\
\text { do departamento de logística e o Responsável pela elaboração dos contratos. } \\
\text { Nas discussões foi dada ênfase ao uso da modelagem } 4 \mathrm{D} \text { como ferramenta } \\
\text { para melhorar a comunicação e a colaboração no processo de tomada de } \\
\text { decisões, principalmente quanto ao plano de ataque da obra. } \\
\text { No } 3^{\circ} \text { workshop (19/01/2016) participaram todos os citados anteriormente. As } \\
\text { discussões deste workshop deram ênfase ao papel estratégico do plano de } \\
\text { cargas para integrar fábrica, expedição e montagem; além de discutir a versão } \\
\text { preliminar da planilha para o planejamento de cargas. }\end{array}$ & \\
\hline
\end{tabular}




\section{Resultados}

Os resultados do estudo estão divididos em dois tópicos, o planejamento logístico do processo de montagem em obra e o planejamento logístico dos suprimentos, de acordo com a divisão proposta por Silva e Cardoso (1998).

\section{Planejamento logístico do processo de montagem em obra}

As decisões sobre os fluxos físicos envolvidos na execução das atividades e a organização do canteiro de obras foram tomadas durante as reuniões de planejamento de curto prazo da Empresa A, com a utilização do modelo BIM 4D. Após as reuniões, o modelo BIM 4D era atualizado. As decisões tomadas eram principalmente relacionadas à definição de equipes, à escolha dos equipamentos necessários, à definição dos acessos e de áreas de estoques, à localização das instalações provisórias e ao traçado de vias de circulação de pedestres e veículos.

Em função do contrato entre a empresa construtora e a Empresa A, no mínimo duas equipes de montagem deveriam sempre permanecer com atividades no canteiro de obras. Com isso, as equipes de montagem e os equipamentos utilizados por elas eram definidos em função da capacidade para atendimento aos prazos estabelecidos e pelas definições contratuais. Por meio da modelagem 4D do processo de montagem foram identificados os equipamentos necessários para a montagem por equipe e as áreas destinadas para possíveis estoques das peças. As peças foram identificadas por cores para representar os lotes definidos para cada equipe, conforme representação nas Figuras 5a e 5b). As Figuras $5 \mathrm{c}$ e $5 \mathrm{~d}$ ilustram o trabalho das equipes e a localização dos equipamentos no canteiro de obras.

Os sistemas pré-fabricados em concreto têm algumas características distintas de outros sistemas industrializados, tais como existência de componentes pesados e o número relativamente pequeno de componentes, tomando sistemas de estrutura metálica como referência. Como consequência, geralmente esses componentes não devem ser estocados em obra, devendo ser içados diretamente do caminhão que os transporta para o local definitivo de uso. Embora a meta seja realizar a montagem a partir da chegada das cargas, é necessário definir áreas mínimas de estoques (Figura 5). Essas áreas, quando possíveis, devem ser localizadas próximas ao local de trabalho das equipes de montagem para evitar movimentações desnecessárias.

Os acessos foram definidos considerando a disponibilidade de espaço para entrada dos equipamentos e, principalmente, para os veículos de grande porte. A rampa de acesso ao canteiro de obras teve sua posição alterada ao longo do período de montagem. A Figura 6 mostra as posições da rampa na modelagem $4 \mathrm{D}$ e fotos com algumas dessas posições. A posição 2 e a posição 3 foram definidas para que a execução das fundações, no local onde estava anteriormente alocada a obra, fosse realizada. A posição 4 foi definida para que as peças fossem diretamente içadas da carreta e montadas, não sendo necessário o descarregamento delas. Para o término da montagem do setor 3, a rampa foi retirada, assim como os equipamentos de montagem que permaneceram no canteiro, por meio de içamento. 
Figura 5 - Planejamento das equipes de montagem
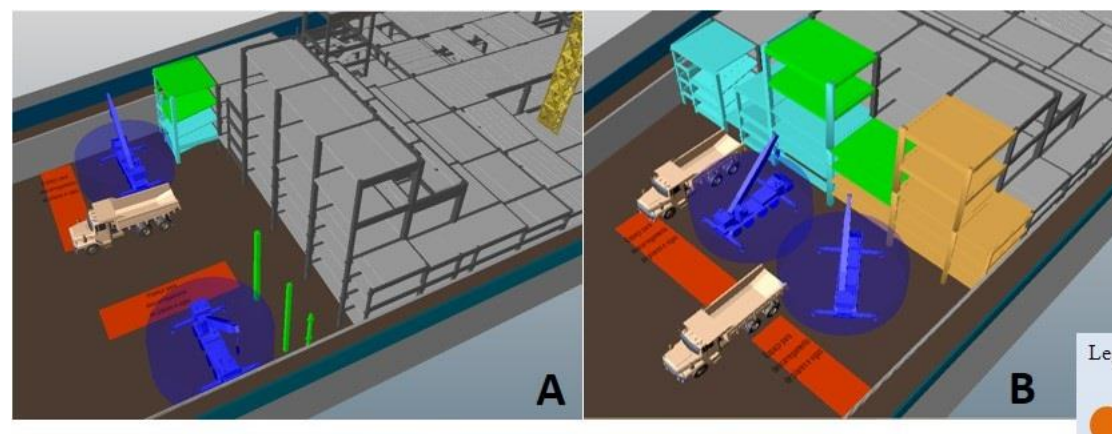

Legenda de cores:
Estoque de

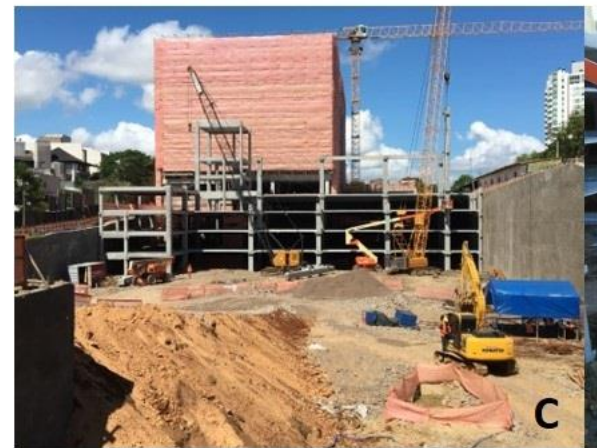

Equipe 1

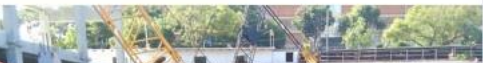

Equipe 2 Trabalho em
progresso

Figura 6 - Posições da rampa de acesso
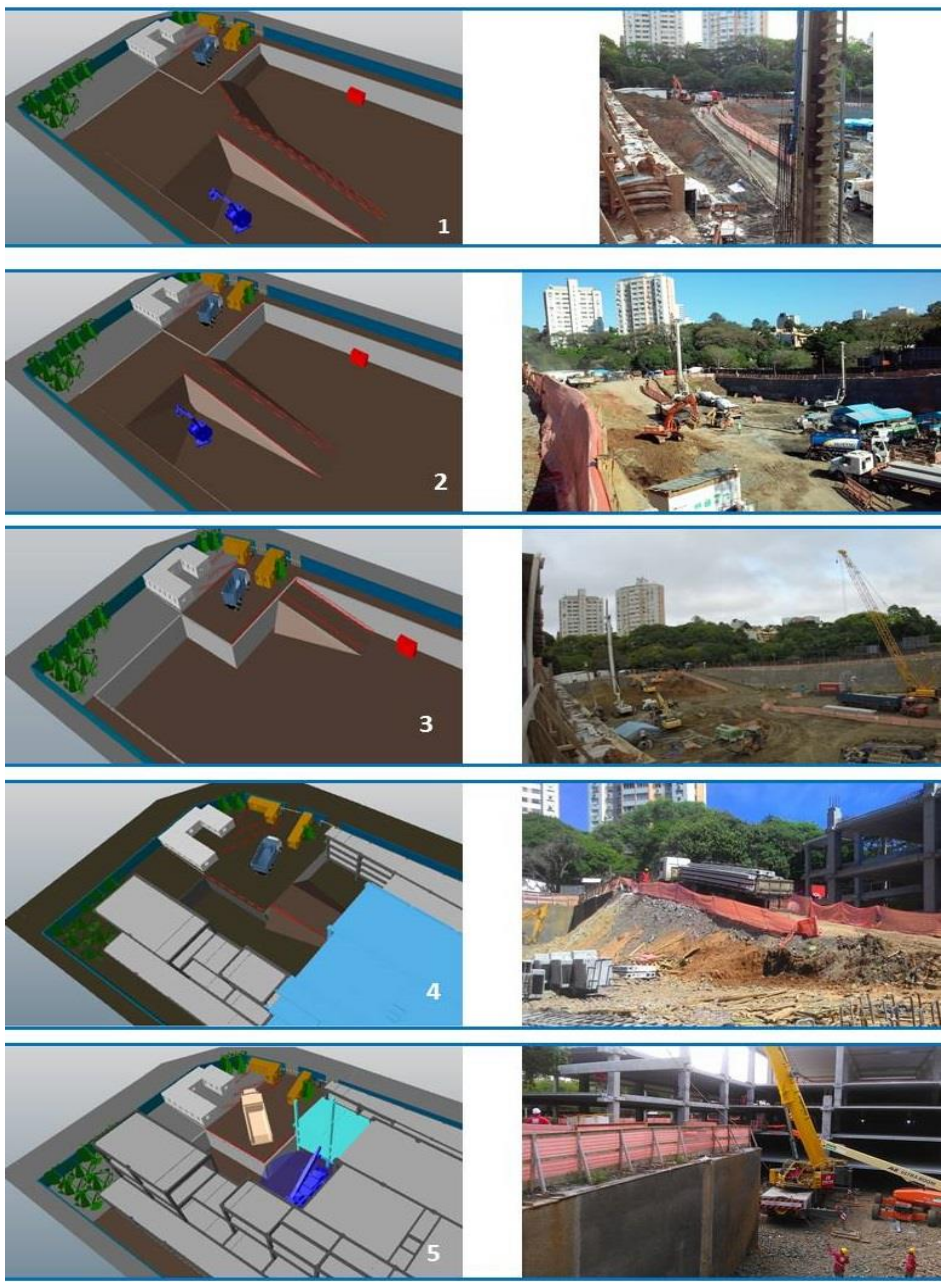
As instalações provisórias também foram posicionadas em lugares de fácil acesso, principalmente porque ferramentas manuais utilizadas pelas equipes eram armazenadas nesses locais. As vias de circulação de pedestres e veículos foram definidas de maneira a evitar interferências entre ambas, o que aumentou a segurança do tráfego.

Juntamente com o estudo dos fluxos físicos, o detalhamento da sequência de montagem foi uma das principais atividades do planejamento logístico, e, a partir deste, foram tomadas decisões sobre a forma de abastecimento de componentes no canteiro e a elaboração dos planos de cargas. O plano de cargas descreve os lotes de componentes que devem ser transportados em uma carga de caminhão e quando deve ser realizada a entrega no canteiro. Além da visualização dinâmica do modelo 4D, foi criado um painel (Figura 7), disponível no escritório da empresa na obra, para explicitar o sequenciamento de montagem de etapas da obra, com indicação da localização da montagem (por eixos definidos em projeto), período de montagem (dias), quantidade de peças e volume total de concreto em cada dia.

\section{Planejamento logístico dos suprimentos}

Com relação ao planejamento logístico dos suprimentos foram implementadas melhorias no processo de planejamento das cargas. A possibilidade de trocas de informações atualizadas a partir do modelo BIM 4D permitiu uma alteração importante no fluxo de informação relacionada aos materiais, possibilitando que mais informações do status do sistema pudessem estar disponíveis e atualizadas.

Foi definido como primeiro passo para a elaboração dos pedidos de componentes por parte do gestor da obra a organização dos elementos presentes em cada quadrante de localização do projeto. A Figura 8 apresenta uma planilha exportada do Synchro PRO para a Microsoft Excel, contendo todos os componentes (representados na coluna Resources), em cada um dos eixos da edificação (representada na coluna Name). Cada linha representa um tipo de produto em um quadrante do projeto. Após a exportação, são extraídos os dados de cada um dos componentes para a elaboração dos planos de carga.

Figura 7 - Painel com o sequenciamento de montagem

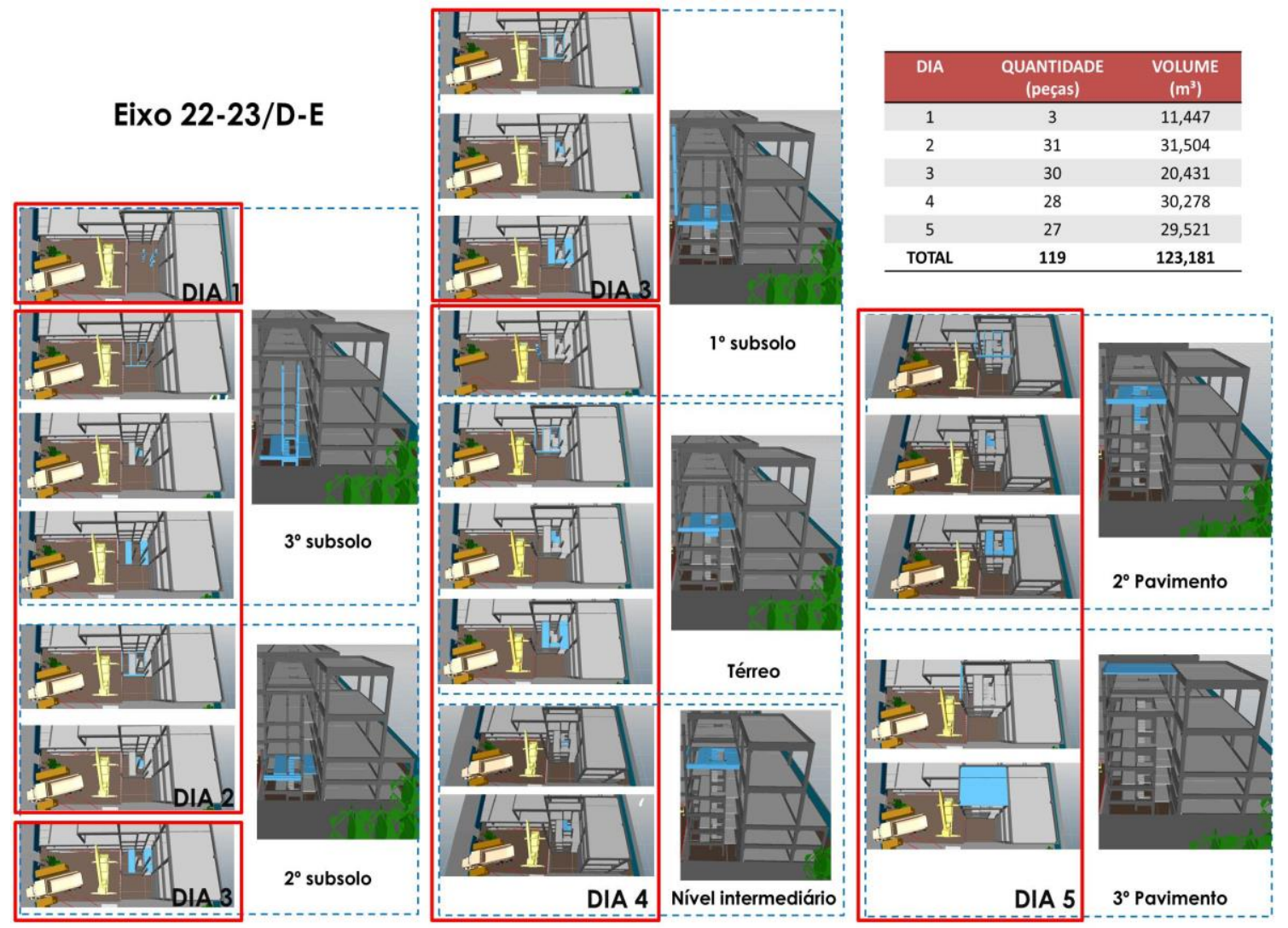


Figura 8 - Planilha com lista de atividades e recursos atribuídos

\begin{tabular}{|c|c|c|c|c|c|}
\hline ID & Name & Duration & Start & Finish & Resources \\
\hline & & - & - & - & 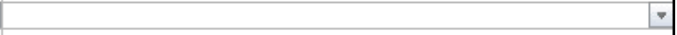 \\
\hline ST00020 & 21/C Pilares & $1 d$ & 28/03/2016 09:00 & 28/03/2016 17:00 & Precast-Rectangular Column with Multi Layer Corbels:PP319:718 \\
\hline ST00030 & $20-21 / \mathrm{B}-\mathrm{C}$ vigas 1 & $1 d$ & 29/03/2016 09:00 & $29 / 03 / 201617: 00$ & Precast-Inverted Tee:VP709:793823_(\#96540) \\
\hline ST00035 & 20-21/B-C lajes 1 & $1 d$ & 29/03/2016 09:00 & 29/03/2016 17:00 & Foundation Slab:LA767:794500_(\#98285), Foundation Slab:LA774 \\
\hline ST00040 & $20-21 / \mathrm{B}-\mathrm{C}$ vigas 2 & $1 d$ & $29 / 03 / 201609: 00$ & $29 / 03 / 201617: 00$ & Precast-Inverted Tee:VP706:762898_(\#78078) \\
\hline
\end{tabular}

Para agregar informações sobre a fabricação dos componentes na planilha anterior, foi utilizado o relatório de status dos componentes (Tabela 1). Uma característica importante desse tipo de sistema construtivo é a existência de repetitividade de componentes. Por exemplo, havia várias lajes com mesmo nome ao longo de diferentes áreas do projeto. Por isso era necessário cruzar as informações semânticas com a localização. Cabe salientar que essa é uma característica que permite reduzir o problema da correspondência mencionado anteriormente.

O planejamento de cargas foi realizado levando-se em consideração as atividades planejadas no canteiro de obras a partir da lista de atividades fornecida pelo modelo 4D (Figura 8) e o relatório de status dos componentes fornecido pela fábrica (Tabela 1). Essas informações eram atualizadas e disponibilizadas frequentemente, e, para isso, foi construída uma terceira planilha, que atualizava automaticamente todas as informações. O desenvolvimento dessa planilha envolveu ciclos de implementação, coleta de dados e análise em um período de três meses, coincidindo com a montagem do setor 3 do empreendimento. A Figura 9 mostra o arranjo das informações da planilha e enfatiza (linha vermelha tracejada) as informações de entrada necessárias.

O comprimento é uma característica muito relevante na elaboração dos planos de cargas. As peças com comprimento maior de $12 \mathrm{~m}$ compõem uma carga especial, denominada carga extensiva. A carga extensiva tem restrições quanto ao horário de transporte, e, por isso, essa informação era destacada na planilha com cor laranja (Figura 9). O status de produção das peças também foi uma informação salientada na planilha. Enquanto a peça não havia sido produzida pela fábrica, a cor do texto era mantida em vermelho (Figura 9).

Para a composição das cargas, os pilares e as vigas poderiam compor uma mesma carga. As demais peças, lajes e escadas somente poderiam ser transportadas com peças de mesmo tipo. Dessa forma, os tipos de carga poderiam ser pilar (PP), viga (VA; VP), pilar e viga $(\mathrm{P}+\mathrm{V})$, laje (LA) e escada (EC). Além disso, havia uma restrição referente ao peso máximo de transporte, que não devia ultrapassar 25 t (Figura 9 - linha tracejada verde).

A Figura 10 é uma representação esquemática da utilização do plano de cargas como ponto de confirmação para a fabricação e para a expedição dos componentes, antes e depois da realização desta pesquisa. Anteriormente à proposta de dois pontos de confirmação, a empresa confirmava apenas o envio dos componentes para a obra, com dois dias de antecedência, período em que os componentes já estavam produzidos e estocados na fábrica. Por essa restrição de tempo, frequentemente as peças contidas no lote de montagem, definido pelo gestor da obra, não eram produzidas a tempo, resultando em atrasos no processo de montagem em obra. Diante disso, a empresa passou a trabalhar com dois pontos de confirmação.

$\mathrm{O}$ primeiro ponto tinha por objetivo confirmar a demanda por produção dos componentes a partir do envio do planejamento das cargas para a fábrica pelo gestor do canteiro com quinze dias de antecedência. Com isso, o setor de planejamento e controle da produção era capaz de fazer uma conferência para confirmar a disponibilidade dos componentes para o período solicitado, apesar de o dimensionamento e reserva da capacidade da fábrica inicial ser baseado no plano-mestre. $\mathrm{O}$ outro ponto de confirmação era o envio do planejamento das cargas para o departamento de expedição com antecedência de dois dias, que tinha como objetivo confirmar a demanda da carga, podendo esta ser acelerada ou atrasada. Essa possibilidade de realizar confirmação para o envio dos componentes permitiu a redução do estoque de componentes na obra. A estratégia dos pontos de confirmação, além de permitir uma confirmação da demanda da obra, representa uma forma de descentralizar o processo de planejamento realizado na matriz da empresa. Com isso, informações atualizadas em ciclos mais curtos de tempo eram disponíveis, e o plano de longo prazo deixa de ser a única fonte de informações para a programação da fábrica. Nesse processo, o BIM 4D auxiliou na geração e atualização das informações quanto às atividades de montagem planejadas pelo gestor do canteiro, sendo essas combinadas com as informações da fabricação e utilizadas para programar as cargas necessárias para o atendimento da demanda da obra. 
Tabela 1 - Extrato do relatório do status das peças

\begin{tabular}{|c|c|c|c|c|c|c|c|c|c|c|c|c|c|c|c|}
\hline \multirow[b]{2}{*}{ Peça } & \multicolumn{3}{|c|}{ Pedido } & \multicolumn{4}{|c|}{ Programado } & \multicolumn{3}{|c|}{ Concretado } & \multicolumn{2}{|c|}{ Acabado } & \multicolumn{3}{|c|}{ Enviado } \\
\hline & Qtde. & Vol.(m3) & Peso $(t)$ & Dep. & Pedido & O.P. & Saldo & Qtde. & Vol.(m3) & Refug. & Final & Liber. & Qtde. & Vol.(m3) & Saldo \\
\hline JNOS-LA-000298 & 1 & 0,61 & 1,50 & 123 & 1 & 1 & 0 & 1 & 0,61 & 0 & 1 & 1 & 0 & 0,00 & 1 \\
\hline JNOS-LA-000299 & 1 & 0,33 & 0,96 & 123 & 1 & 1 & 0 & 1 & 0,33 & 0 & 1 & 1 & 1 & 0,33 & 0 \\
\hline JNOS-LA-000310 & 6 & 3,69 & 9,06 & 123 & 6 & 6 & 0 & 6 & 3,69 & 0 & 6 & 6 & 0 & 0,00 & 6 \\
\hline JNOS-LA-000311 & 3 & 1,40 & 3,45 & 123 & 3 & 3 & 0 & 3 & 1,40 & 0 & 3 & 3 & 0 & 0,00 & 3 \\
\hline
\end{tabular}

Figura 9 - Planilha para o planejamento das cargas

\begin{tabular}{|c|c|c|c|c|c|c|c|c|c|c|c|c|c|c|c|}
\hline \multirow{2}{*}{\multicolumn{3}{|c|}{ 22-23/D-E }} & \multirow{2}{*}{$\begin{array}{c}22-23 \\
D-E\end{array}$} & & & \multirow{2}{*}{$\begin{array}{l}\text { Peso Total } \\
\text { Extensiva? }\end{array}$} & \multicolumn{2}{|c|}{74,32 ton } & \multirow{5}{*}{$\begin{array}{l}+ \\
\text { 离 } \\
\frac{6}{8}\end{array}$} & \multirow{2}{*}{$\begin{array}{l}O_{1} \\
O_{2}\end{array}$} & \multicolumn{2}{|c|}{ 21,11 Extensiva } & 0 & & \\
\hline & & & & \multicolumn{2}{|c|}{ Tipos de peças } & & \multicolumn{2}{|l|}{ Sim } & & & 12,28 & Comum & ) & & \\
\hline \multicolumn{3}{|c|}{$L$} & 0 & 2 & & Total de & \multicolumn{2}{|c|}{5 Cargas } & & \multirow{3}{*}{$\begin{array}{l}\mathrm{O}_{3} \\
\mathrm{O}_{4} \\
\mathrm{O}_{5}\end{array}$} & \multirow{3}{*}{\multicolumn{2}{|c|}{$\begin{array}{r}21,63 \text { Comum } \\
8,35 \text { Comum } \\
10,95 \text { Comum }\end{array}$}} & \multirow{3}{*}{\multicolumn{2}{|c|}{$\begin{array}{l}0 \\
0 \\
0\end{array}$}} & \\
\hline \multirow{2}{*}{\multicolumn{3}{|c|}{$T$}} & \multirow{2}{*}{\multicolumn{3}{|c|}{ (segundo andar opcional) }} & \multirow[t]{2}{*}{ Cargas } & \multirow{2}{*}{\multicolumn{2}{|c|}{$\begin{array}{l}4 \text { Comum } \\
1 \text { Extensiva }\end{array}$}} & & & & & & & \\
\hline & & & & & & & & & & & & & & & \\
\hline$\nabla$ & $v$ & & $\checkmark$ Plant $v$ & EIXO - & QTDE $\vee$ & PESO un $\mathrm{v}$ & VOLUME ur $\vee$ & $\mathrm{COMP}_{\mathrm{V}}$ & $\nabla$ & DATA V & ESOIV & VOL tol $\mathbf{V}$ & PRODUZIDIF & Tip $\mathbf{v}$ & Carg \\
\hline 1 & $\mathrm{PP}$ & 331 & L & $22-23 / D-E$ & 1 & 10,4 & 4,161 & 19,13 & & $18 / a b r$ & 10,4 & 4,161 & $O K$ & $P+V$ & 1 \\
\hline 2 & $\mathrm{PP}$ & 333 & L & $22-23 / D-E$ & 1 & 10,71 & 4,285 & 19,13 & & $18 / a b r$ & 10,71 & 4,285 & $O K$ & $P+V$ & 1 \\
\hline 1 & EC & 014 & $T$ & $22-23 / D-E$ & 1 & 6,14 & 2,456 & 5,93 & & $19 / a b r$ & 6,14 & 2,456 & $O K$ & $E C$ & 2 \\
\hline 2 & EC & 015 & $T$ & $22-23 / D-E$ & 1 & 6,14 & 2,454 & 5,93 & & $19 / a b r$ & 6,14 & 2,454 & $O K$ & $E C$ & 2 \\
\hline 3 & VP & 711 & $T$ & $22-23 / D-E$ & 2 & 4,5 & 1,801 & 7,32 & & $19 / a b r$ & 9 & 3,602 & $O K$ & $P+V$ & 3 \\
\hline 4 & VP & 733 & $T$ & $22-23 / D-E$ & 1 & 4,53 & 1,812 & 7,13 & & $19 / a b r$ & 4,53 & 1,812 & NÃO & $P+V$ & 3 \\
\hline 5 & VP & 762 & $T$ & $22-23 / D-E$ & 1 & 3,57 & 1,429 & 7,48 & & $19 / a b r$ & 3,57 & 1,429 & $O K$ & $P+V$ & 3 \\
\hline
\end{tabular}

Figura 10 - Esquema da estratégia dos pontos de confirmação

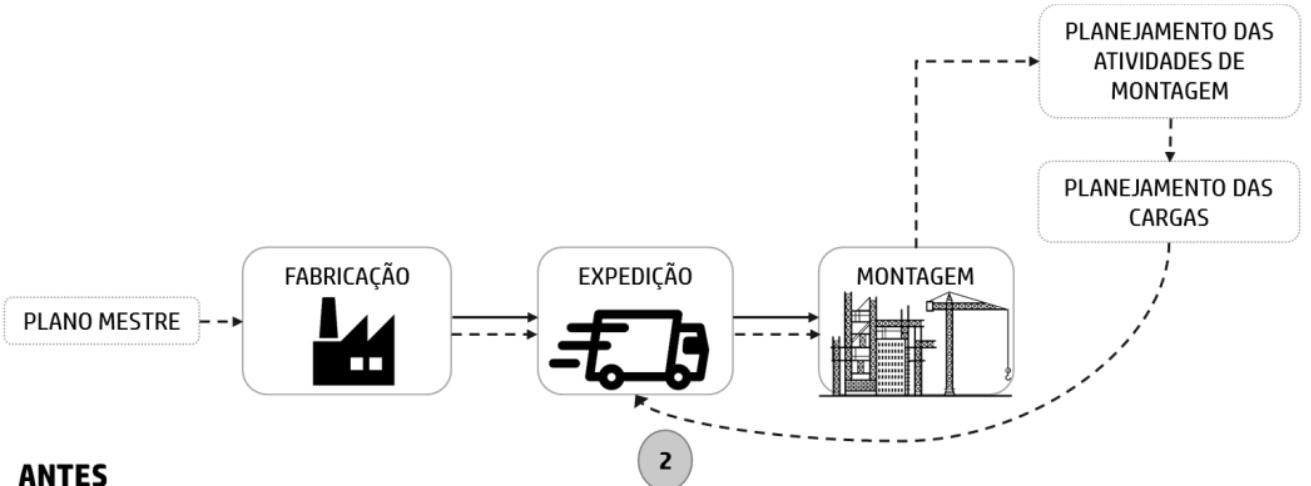

ANTES

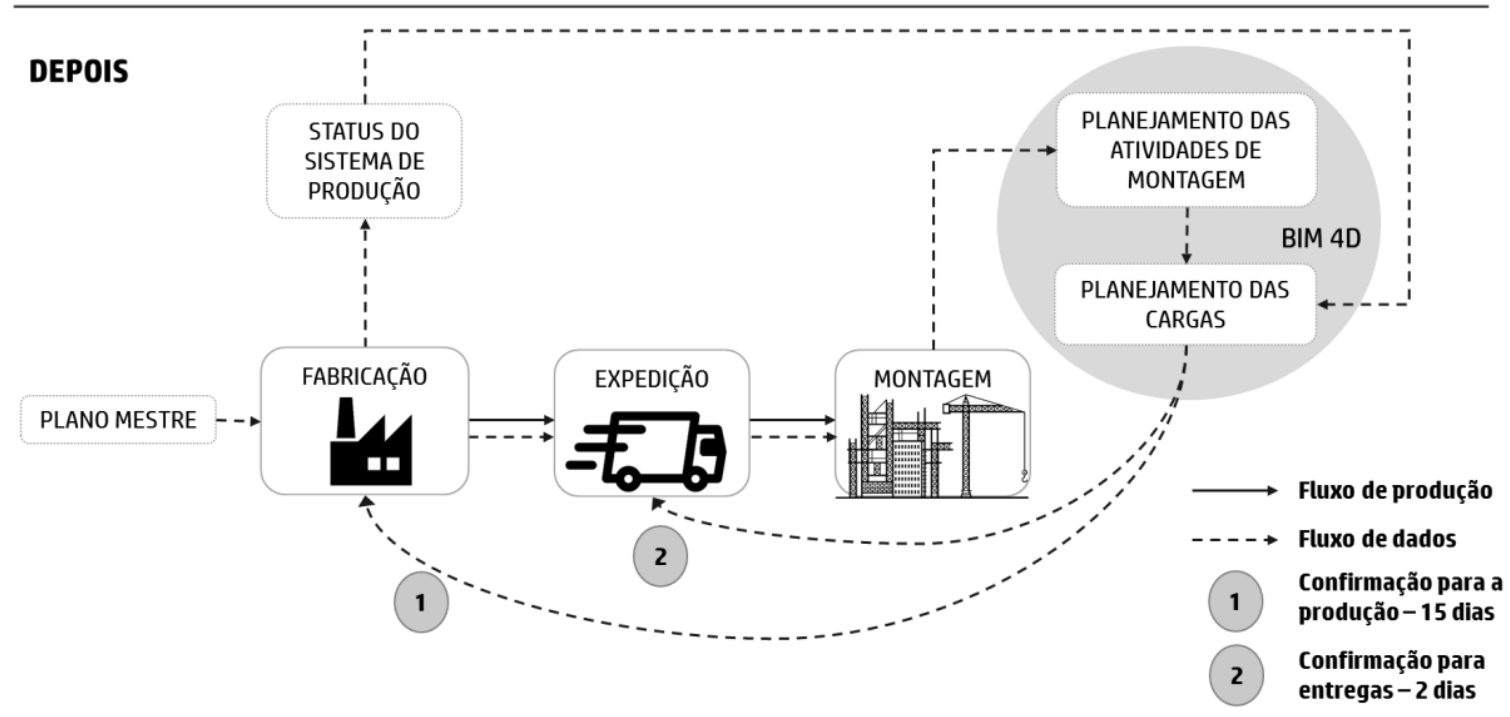

BIM 4D aplicado à gestão logística: implementação na montagem de sistemas pré-fabricados de concreto Engineer- 
Na Figura 11 são apresentados os resultados obtidos em relação à eficácia na entrega de cargas e a produtividade para cada etapa do processo de montagem. A maximização da utilização da capacidade era um dos objetivos principais do planejamento e controle da produção na fábrica. Por essa razão, a produção de pilares e vigas era realizada em grandes lotes com a intenção de otimizar o uso das formas, que eram de madeira, assim como as vigas protendidas para utilização da capacidade máxima da pista. Com isso, a programação e a produção de partes pertencentes a fases subsequentes do projeto e, muitas vezes, indefinidas pelo cliente resultavam em uma grande quantidade de estoque no pátio da fábrica. Essa prática de definir a sequência de produção considerando somente as necessidades da fábrica influenciava o sequenciamento de montagem das peças no canteiro de obras, resultando no baixo atendimento à demanda da obra, representado na Figura 11 pelo total de cargas entregues nos setores 1 e 2 .

Ao analisar a Figura 11, nota-se um aumento na quantidade de cargas planejadas para o setor 3, comparado aos anteriores, bem como aumento da produtividade das equipes. As melhorias no processo de planejamento das cargas bem como o uso dos pontos de confirmação influenciaram a troca de informações entre a fábrica e a obra. O atendimento aos prazos de entrega pela fábrica, que foi de $95 \%$ das solicitações da obra, resultou no cumprimento dos prazos das atividades de montagem no canteiro.

\section{Diretrizes propostas}

A partir dos resultados do estudo empírico foi proposto um conjunto de diretrizes para auxiliar empresas no processo de implementação do BIM 4D. Tais diretrizes enfatizam o papel dos modelos BIM 4D em reunir informações sobre o produto e os processos de forma a contribuir para aumentar a confiabilidade das informações e melhorar a eficácia de seu compartilhamento.

\section{Padronização dos processos logísticos}

\section{Definir o escopo das informaç̃es para o desenvolvimento do modelo BIM 4D para apoiar a gestão logística}

O modelo deve conter um escopo de informações bem definidas, úteis e compreensíveis para a tomada de decisões por parte dos distintos usuários envolvidos. O principal usuário potencial do modelo é o gestor da obra, porém outros usuários, tais como coordenadores e engenheiros de outras empresas, mestres de obras, subempreiteiros e até mesmo operários, podem participar das reuniões de planejamento.

As informações necessárias relacionam-se aos componentes da estrutura pré-fabricada, incluindo dados de identificação da peça, localização e orientação da peça em função dos eixos definidos, assim como com o canteiro de obras e entornos, incluindo os acessos à obra, áreas de estoque e equipamentos utilizados pela equipe de montagem.

\section{Figura 11 - Síntese referente ao planejamento das cargas por setor de montagem}

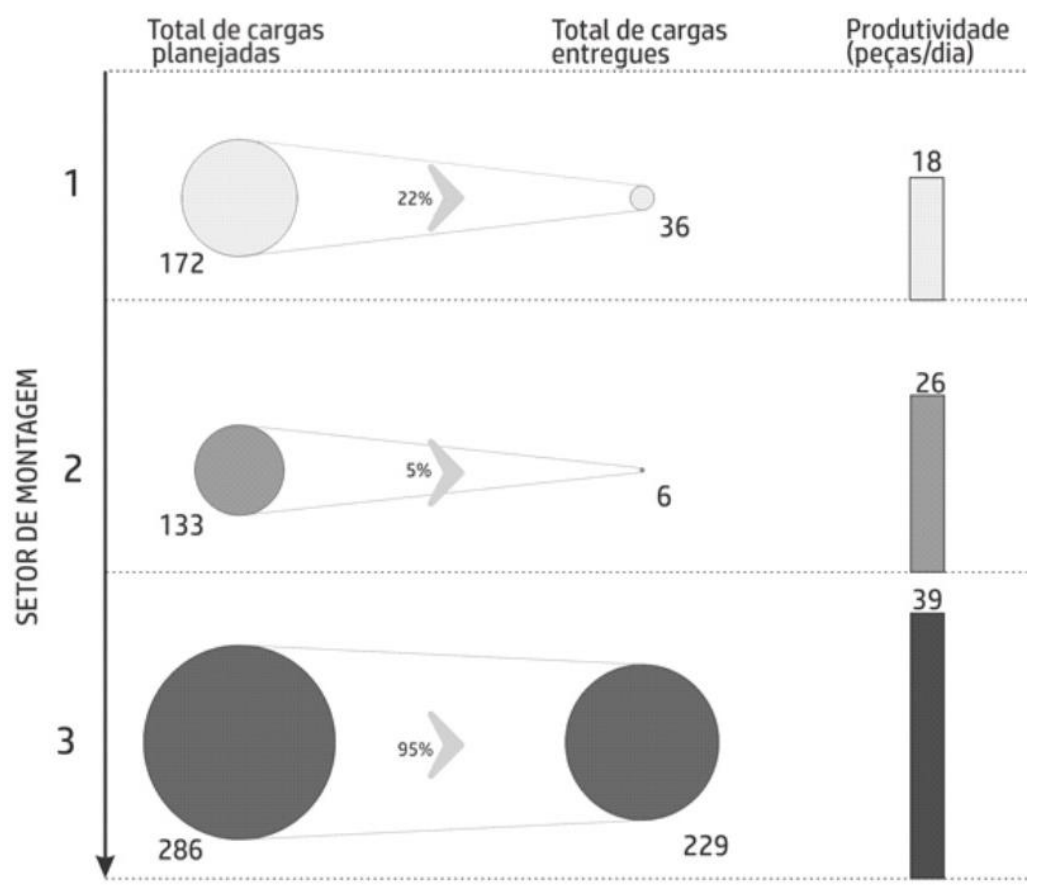


O nível de desenvolvimento do modelo 3D deve ser definido de acordo com o objetivo de aplicação dos modelos 4D em função das implicações no tempo gasto para a criação dos modelos (HEESOM; MAHDJOUBI, 2004).

A partir deste trabalho, recomenda-se o LOD 300 para os componentes da estrutura pré-fabricada e 200 para os elementos do canteiro de obras. É importante também que seja criada uma biblioteca de objetos BIM com os padrões da empresa, de forma a contribuir para a redução do tempo de modelagem dos componentes do projeto. Além disso, deve ser definida uma padronização de códigos para os componentes modelados e uma nomenclatura para as atividades de montagem. Sugere-se que a nomenclatura adotada nos projetos estruturais seja compatível com o padrão adotado para cadastro das peças no sistema da empresa utilizado para gerar as ordens de produção e de compras. Com a adoção de padrões de nomenclatura para as atividades de montagem, pode-se melhorar a troca de informações entre os diferentes níveis hierárquicos do planejamento. Finalmente, podem-se adotar códigos de cores para etapas ou frentes de trabalho, o que permite a identificação mais rápida dos lotes de montagem.

\section{Fomentar a colaboração a partir de processos participativos}

Usualmente, as tomadas de decisões para ações corretivas e revisões de planos ocorrem em reuniões de planejamento, devendo haver a participação de diversos intervenientes com interesses distintos, e, por isso, as informações precisam ser comunicadas de forma fácil e rápida entre os participantes (FARD et al., 2009). A modelagem 4D deve ser feita de forma a contribuir para a criação de um ambiente adequado para a introdução de processos colaborativos nas reuniões de planejamento, gerando discussões e melhor entendimento dos processos de montagem pelos intervenientes. A colaboração entre vários intervenientes pode contribuir para aumentar a confiabilidade dos planos e a aderência aos padrões estabelecidos.

\section{Uso de dispositivos visuais para disseminar informações}

Além da visualização dos modelos no formato digital (vídeos), o uso de dispositivos visuais a partir do modelo 4D pode ser usado para a disseminação de informações relevantes. Podem ser criados snapshots para representação de detalhes específicos. A disponibilidade de informações ao público por meio de dispositivos visuais torna o processo diretamente observável, aumentado a transparência do processo e contribuindo para a visibilidade dos possíveis erros (KOSKELA, 1992). São exemplos dessa utilização a elaboração de painéis com imagens do modelo 4D (Figura 7) contendo detalhes da sequência de execução da montagem e os registros fotográficos realizados em campo (Figuras 12b e 12d), que permitiram a comparação entre as informações das atividades planejadas e executadas (Figuras 12a e 12c).

\section{Figura 12 - Comparação entre o plano (A, C) e a execução (B, D)}
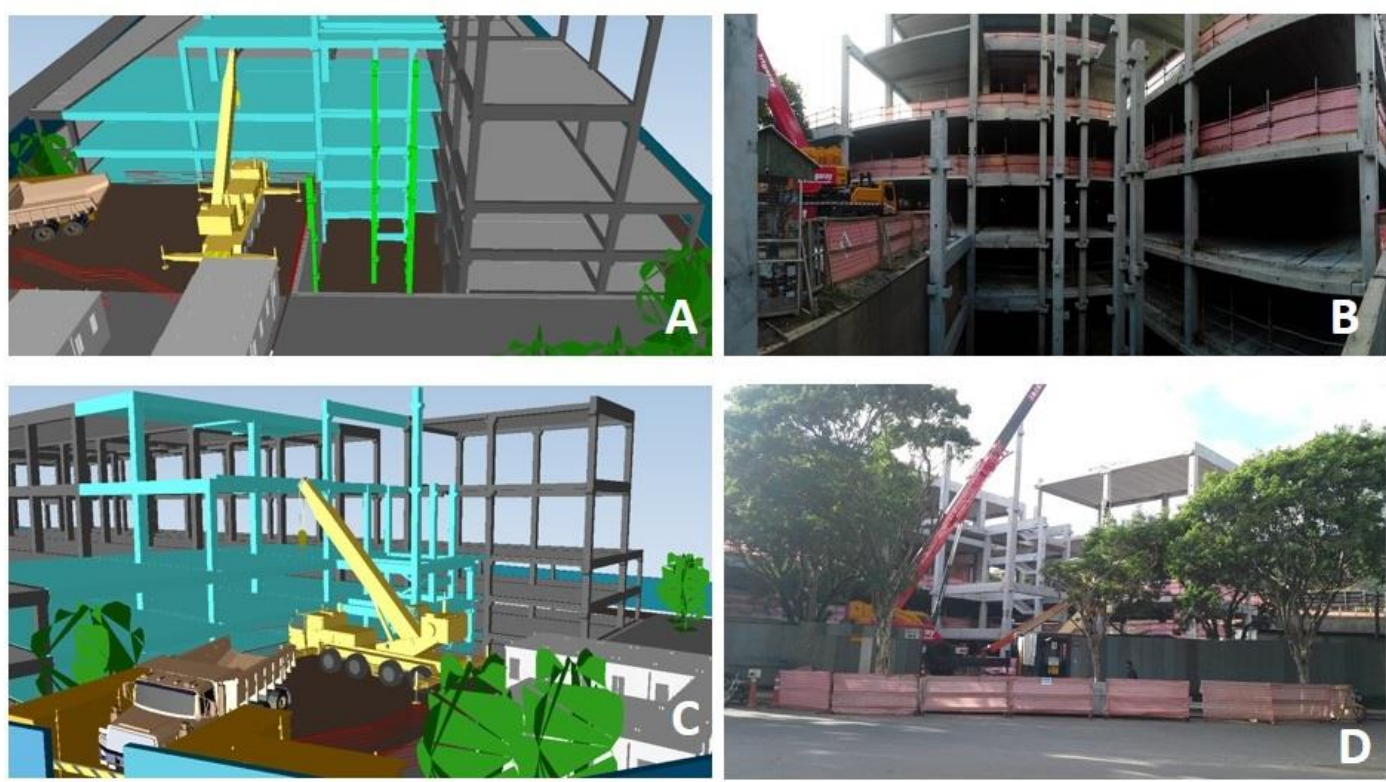


\section{Adotar a produção puxada}

\section{Analisar o status do sistema e controlar o trabalho em progresso}

A existência de incertezas no canteiro de obras, tais como indefinições no projeto do empreendimento e mudanças no sequenciamento de atividades predecessoras, faz com que o plano de longo prazo, definido nos estágios iniciais do empreendimento, não possa ser seguido. Assim, há necessidade de definição de pontos de confirmação na produção de peças na fábrica e também na entrega de componentes na obra para evitar o aumento do trabalho em progresso. Dessa forma, os planos de longo prazo devem servir para estabelecer uma reserva de capacidade da fábrica em vez de empurrar a produção de peças e entregá-las na obra.

Tais confirmações dependem do conhecimento do status da obra e também da fabricação de peças na fábrica, conforme o conceito de produção puxada proposto por Hopp e Spearman (2000). Por meio desses pontos de confirmação podem-se evitar estoques excessivos na fábrica e no canteiro de obras.

\section{Integrar o uso do modelo BIM 4D e decisões de logística aos diferentes níveis de planejamento e controle da produção}

Com relação à modelagem 4D no nível de longo prazo, as principais decisões são a divisão da obra em etapas e a definição do plano de ataque inicial. A partir disso é possível definir prazos de execução e datas-marcos, sendo essas informações utilizadas pela fábrica para a reserva de sua capacidade para atender à obra. Com a definição do plano de ataque podem ser realizadas definições dos fluxos físicos em um nível pouco detalhado em função das incertezas ainda existentes.

No nível de médio prazo, a modelagem 4D pode ser utilizada para a análise de restrições relacionada aos processos logísticos da obra. Além disso, o sequenciamento da montagem pode ser detalhado, pois é necessário definir com mais precisão os lotes de montagem e, consequentemente, os lotes de fabricação e transporte. Devem-se definir lotes relativamente pequenos e flexíveis, considerando a capacidade das equipes de montagem e também da fábrica e de transporte. Tais definições têm um importante papel no controle do fluxo de materiais e na sincronização entre as atividades da fábrica e a montagem no canteiro de obras. Por um lado, os atrasos na entrega dos componentes podem gerar custos onerosos ao canteiro de obras, relacionados a mão de obra e a equipamentos parados, e, por outro, a produção e a entrega antecipadas tendem a aumentar os custos com a movimentação e estoque de peças na obra, podendo também afetar outros empreendimentos abastecidos pela mesma fábrica (ČUŠ-BABIČ et al., 2014).

Por fim, o último nível hierárquico compreende a definição dos pacotes de trabalho e confirmação de envio dos componentes pela fábrica a partir do status da produção pelas equipes de montagem. A visualização do modelo BIM 4D pode auxiliar na tomada de decisão no curto prazo.

\section{Integrar as informações de fabricação e montagem no canteiro de obras}

Considerando a necessidade de utilizar informações do projeto, assim como o status da obra e a disponibilidade de peças na expedição da fábrica, a tecnologia da informação e, particularmente, os modelos BIM podem ser utilizados para integrar e atualizar as informações para apoiar a tomada de decisão. Conforme Eastman et al. (2011), existe a necessidade de informações precisas, confiáveis e atualizadas para gerenciar o fluxo de produtos em qualquer cadeia de suprimentos. No presente trabalho a integração entre as informações da fabricação e as da montagem dos componentes resultou em consideráveis melhorias no planejamento logístico.

\section{Conclusões}

O presente artigo propôs um conjunto de diretrizes para a utilização do BIM 4D e conceitos e princípios da Produção Enxuta para apoiar a gestão logística do processo de montagem de sistemas construtivos pré-fabricados em concreto do tipo ETO.

Como primeira contribuição destaca-se o uso das informações da modelagem BIM 4D combinadas com as informações da fabricação que possibilitam analisar o status do sistema, contribuindo para a integração de duas unidades de produção, a fábrica e a obra. A eficácia do planejamento em sistemas de produção ETO depende da sincronização entre os processos de fabricação e montagem, devendo as reais necessidades do canteiro de obras ser consideradas no planejamento da produção de componentes e de operações logísticas (Figura 10).

No estudo empírico realizado, as melhorias no fluxo e compartilhamento das informações entre os intervenientes e, principalmente, entre os dois locais de produção resultaram no aumento na confiabilidade das informações geradas e em ganhos substanciais na produtividade das equipes. Esses ganhos ocorreram devido ao atendimento da demanda da obra pela fábrica e contribuíram para a solução de alguns problemas típicos de sistemas pré-fabricados do tipo ETO apontados na literatura, tal como a falta de confiabilidade do planejamento 
do processo de montagem em função da comunicação insuficiente entre fábrica e obra.

Outra contribuição refere-se à necessidade de definição de pontos de confirmação da demanda. Nesse sentido, os planos de cargas podem ser utilizados para confirmar a necessidade por produção de componentes e controlar o fluxo de materiais, evitando o excesso de estoques tanto na fábrica como no canteiro de obras. Também foi possível alinhar os planos de curto prazo com o planejamento das cargas: ao realizar o planejamento das atividades de montagem com o apoio da modelagem BIM 4D eram definidos os lotes e a sequência de montagem, utilizados também como lotes de fabricação e transporte. Na interface entre o PCP e a gestão logística destacam-se os avanços obtidos em relação à redução do tamanho do lote e à padronização de algumas operações logísticas.

Embora a modelagem 4D tenha sido realizada pela equipe de pesquisadores, houve forte participação da equipe envolvida na gestão do processo de montagem, incluindo o gestor da obra e o engenheiro de planejamento da empresa construtora. A participação dos envolvidos permitiu a realização de análises críticas e solicitações de alteração na sequência de montagem, bem como decisões sobre os fluxos físicos e a organização do canteiro de obras, evidenciando um dos principais benefícios da adoção do BIM, que é tornar o ambiente de trabalho mais colaborativo. Dessa forma, o BIM 4D não foi importante somente para fins de visualização, mas também pela integração e compartilhamento de informações relevantes para gestores, o que contribuiu para a padronização dos processos logísticos. A disponibilidade de informações sobre o status da montagem e a possibilidade de realizar rápidas alterações nos planos com o apoio da modelagem BIM 4D tornaram o processo de tomada de decisão referente à gestão logística mais eficaz.

Como sugestões de trabalhos futuros podem-se apontar:

(a) desenvolver estudos que contribuam para gerenciar a interface das atividades de montagem com as atividades dos demais intervenientes da produção atuantes no canteiro de obras por meio da tecnologia da informação, com análise dos fluxos de trabalho e interações entre os processos;

(b) investigar como melhorias no processo de desenvolvimento do produto visando à padronização e modularização de componentes poderiam influenciar no desempenho da produção e montagem de sistemas pré-fabricados; e

(c) investigar os impactos dos atrasos das entregas e da montagem dos componentes pré- fabricados no custo do empreendimento a partir de uma análise detalhada da utilização da capacidade dos recursos (mão de obra e equipamentos).

\section{Referências}

AGAPIOU, A. et al. The Role of Logistics in the Materials Flow Control Process. Construction Management and Economics, v. 16, n. 2, p. 131137, 1998.

BALLARD, G.; HOWELL, G. What Kind of Production is Construction? In: ANNUAL CONFERENCE INTERNATIONAL GROUP FOR LEAN CONSTRUCTION, 6., Guaruja, 1998. Proceedings... Guaruja, 1998a.

BALLARD, G.; HOWELL, G. Shielding Production: essencial step in production control. Journal of Civil Engineering and Management, v. 124, n. 1, p. 11-17, 1998b.

BAtaglin, F. S. Modelo Para Gestão dos Processos Logísticos em Obras de Sistemas PréFabricados Engineer-to-order. Porto Alegre, 2017. Dissertação (Mestrado em Engenharia Civil) - Program de Pós-graduação em Engenharia Civil, Universidade Federal do Rio Grande do Sul, Porto Alegre, 2017.

BIMFORUM. LOD | BIMForum. Disponível em: <http://bimforum.org/lod/>. Acesso em: 18 abr. 2016.

BIOTTO, C. N.; FORMOSO, C. T.; ISATTO, E. L. Uso de Modelagem 4D e Building Information Modeling na Gestão de Sistemas de Produção em Empreendimentos de Construção. Ambiente Construído, Porto Alegre, v. 15, n. 2, p. 79-96, abr./jun. 2015.

BORJEGHALEH, R. M.; SARDROUD, J. M. Approaching Industrialization of Buildings and Integrated Construction Using Building Information Modeling. Procedia Engineering, v. 164, p. 534-541, ju. 2016.

BORTOLINI, R. Modelo Para Planejamento e Controle Logístico de obras de sistemas préfabricados do tipo engineer-to-order com o uso de BIM 4D. Porto Alegre, 2015. Dissertação (Mestrado em Engenharia Civil) - Program de Pósgraduação em Engenharia Civil, Universidade Federal do Rio Grande do Sul, Porto Alegre, 2015.

BRITO, D. M.; FERREIRA, E. A. M. Strategies for Representation and Analyses of 4D Modeling Applied to Construction Project Management. Procedia Economics and Finance, v. 21, n. 15, p. 374-382, 2015. 
CHAN, W.-T.; ZENG, Z. Coordinated Production Scheduling of Prefabricated Building Components. In: CONSTRUCTION RESEARCH CONGRESS: WIND OF CHANGE: INTEGRATION AND INNOVATION, Salt Lake City, 2004. Proceedings... Salt Lake City, 2004.

CHOI, B. et al. Framework for Work-Space Planning Using Four-Dimensional BIM in Construction Projects. Journal of Construction Engineering and Management, v. 140, n. 9, p. 4014041, 2014.

ČUŠ-BABIČ, N. et al. Supply-Chain Transparency Within Industrialized Construction Projects. Computers in Industry, v. 65, n. 2, p. 345-353, 2014.

DEFFENSE, J.; CACHADINHA, N. Lean Production in the Precast Concrete Components' Industry. In: ANNUAL CONFERENCE OF THE INTERNATIONAL GROUP FOR LEAN CONSTRUCTION, 19., Lima, 2011.

Proceedings... Lima, 2011.

EASTMAN, C. et al. BIM Handbook: a guide to Building Information Modeling for Owners, Managers, Designers, Engineers, and Constractors. New York: John Wiley \& Sons, 2011.

ERGEN, E.; AKINCI, B. Formalization of the Flow of Component-Related Information in Precast Concrete Supply Chains. Journal of Construction Engineering and Management, v. 134, n. 2, p. 112-121, 2008.

FARD, M. G. et al. Visualization of Construction Progress Monitoring with 4D Simulation Model Overlaid on Time-Lapsed Photographs. Journal of Computing in Civil Engineering, v. 23, n. 6, p. 391-404, 2009.

HARRIS, B.; ALVES, T. D. C. L. 4D Building Information Modeling and field operations: an exploratory study. In: ANNUAL CONFERENCE OF THE INTERNATIONAL GROUP FOR LEAN CONSTR. 21., Fortaleza, 2013. Proceedings... Fortaleza, 2013.

HEESOM, D.; MAHDJOUBI, L. Trends of 4D CAD Applications for Construction Planning. Construction Management and Economics, v. 22, n. 2, p. 171-182, 2004.

HOLMSTROM, J.; KETOKIVI, M.; HAMERI, A.-P. Bridging Practice and Theory: a design science approach. Decision Science, v. 40, n. 1, p. 65-87, 2009.

HOPP, W.; SPEARMAN, M. Factory Physics. $2^{\text {nd }}$. ed. New York: McGraw-Hill/Irwin, 2000.
HOPP, W.; SPEARMAN, M. To Pull or Not to Pull: what is the question? Manufacturing and Service Operations Management, v. 6, n. 2, p. 133-148, 2004.

JOHNSTON, R. B. B.; BRENNAN, M. Planning or Organizing: the implications of theories of activity for management of operations. Omega, v. 24, n. 4, p. 367-384, 1996.

KASSEM, M.; DAWOOD, N.; CHAVADA, R. Construction Workspace Management Within an Industry Foundation Class-Compliant 4D tool. Automation in Construction, v. 52, p. 42-58, abr. 2015.

KOSKELA, L. Application of the New Philosophy to Construction. Stanford: Stanford University, 1992.

KOSKELA, L. Is Structural Change the Primary Solution to the Problems of Construction? Building Research \& Information, v. 31, n. 2, p. 85-96, 2003.

LEE, S.; YU, J.; JEONG, D. BIM Acceptance Model in Construction Organizations. Journal of Management in Engineering, v. 31, n. 1988, p. 4014048, 2013.

LESSING, J. .; STEHN, L. .; EKHOLM, A. . Industrialised Housing: definition and categorization of the concept. In: ANNUAL CONFERENCE OF THE INTERNATIONAL GROUP FOR LEAN CONSTRUCTION, 13., Sydney, 2005. Proceedings... Sydney, 2005.

LI, Y.; STEPHENS, J.; RYBA, A. Four-

Dimensional Modelling on Tottenham Court Road station, London, UK. Proceedings of the

Institution of Civil Engineers, v. 167, n. 5, p. 33, 2014.

MATT, D. T.; DALLASEGA, P.; RAUCH, E. Synchronization of the Manufacturing Process and On-Site Installation in ETO Companies. Procedia CIRP, v. 17, p. 457-462, 2014.

MATT, D. T.; DALLASEGA, P.; RAUCH, E. OnSite Oriented Capacity Regulation for Fabrication Shops in Engineer-to-Order Companies (ETO). Procedia CIRP, v. 33, p. 197-202, 2015.

MCGOVERN, T.; HICKS, C.; EARL, C. F. Modelling Supply Chain Management Processes in Engineer-to-Order Companies. International Journal of Logistics Research and Applications: A Leading Journal of Supply Chain Management, v. 2, n. 2, p. 147-159, 1999.

PAPADAKI, I. N.; CHASSIAKOS, A. P. MultiObjective Construction Site Layout Planning Using Genetic Algorithms. Procedia Engineering, v. 164, p. 20-27, 2016. 
PAPADONIKOLAKI, E.; VRIJHOEF, R.; WAMELINK, H. Supply Chain Integration With BIM: a graph-based model. Structural Survey, v. 33 , n. 3, p. 257-277, 2015.

PHENG, L. S.; CHUAN, C. J. Just-in-Time Management of Precast Concrete Components. Journal of Construction Engineering and Management, p. 494-501, dec. 2001.

PITAKE, S. A.; PATIL, P. D. S. Visualization of Construction Progress by 4D Modeling Application. International Journal of Engineering Trends and Technology (IJETT), v. 4, n. 7, p. 3000-3005, 2013.

POWELL, D. et al. A New Set of Principles for Pursuing the Lean Ideal in Engineer-To-Order Manufacturers. Procedia CIRP, v. 17, p. 571-576, 2014.

SACKS, R. et al. Interaction of Lean and Building Information Modeling in Construction. Journal of Construction Engineering and Management, v. 136, n. 9, p. 968-980, 2010.

SERRA, S. M. B.; OLIVEIRA, O. J. Development of the Logistics Plans in Building Construction. In: INTERNATIONAL CONFERENCE ON STRUCTURAL AND CONSTRUCTION ENGINEERING, 2., Rome, 2003. Proceedings... Rome, 2003.

SILVA, F. DA; CARDOSO, F. Applicability of Logistics Management in Lean Construction: a case study Approach in Brazilian building companies. In: ANNUAL CONFERENCE OF THE INTERNATIONAL GROUP FOR LEAN CONSTR, 7., Berkeley, 1998. Proceedings... Berkeley, 1998.

SKJELBRED, S.; FOSSHEIM, M. E.;

DREVLAND, F. Comparing Different Approaches to Site Organization and Logistics: Multiple Case Studies. In: ANNUAL CONFERENCE OF THE INTERNATIONAL GROUP FOR LEAN CONSTRUCTION, 23., Perth, 2015. Proceedings... Perth, 2015.
SUSMAN, G. I.; EVERED, R. D. An Assessment of the Scientific Merits of Action Research. Administrative science quarterly, v. 23, n. 4, p. 582-603, 1978.

THIOLLENT, M. Metodologia da PesquisaAção. 14 ed. São Paulo: Cortez, 2005.

TOMMELEIN, I. D. Pull-Driven Scheduling for Pipe-Spool Installation: simulation of lean construction technique. Journal of Construction Engineering and Management, v. 124, n. 4, p. 279-288, 1998.

TREVISAN, G. dos S. Diretrizes Para a Gestão Logística em Empresas Engineer-to-Order de Pré - Fabricados na Construção. Porto Alegre, 2016. Dissertação (Mestrado em Engenharia Civil) - Programa de Pós-graduação em Engenharia Civil, Universidade Federal do Rio Grande do Sul, Porto Alegre, 2016.

VAN AKEN, J. E. Management Research on the Basis of the Design Paradigm: the Quest for Fieldtested and Grounded Technological Rules.

Journal of Management Studies, v. 41, n. 2, p. 219-246, 2004.

VIANA, D. D. Integrated Production Planning and Control Model for Engineer-to-Order Prefabricated Building Systems. Porto Alegre, 2015. Tese (Doutorado em Engenharia Civil) Programa de Pós-graduação em Engenharia Civil, Universidade Federal do Rio Grande do Sul, Porto Alegre, 2015.

YU, Q.; LI, K.; LUO, H. A BIM-Based Dynamic Model For Site Material Supply. Procedia Engineering, v. 164, p. 526-533, jun. 2016.

ZHAI, Y.; ZHONG, R. Y.; HUANG, G. Q. Towards Operational Hedging For Logistics Uncertainty Management in Prefabrication Construction. IFAC-PapersOnLine, v. 48, n. 3, p. 1128-1133, 2015.

ZHANG, J.; LI, D. Research on 4D Virtual Construction and Dynamic Management System Based on BIM. In: INTERNATIONAL CONFERENCE ON COMPUTING IN CIVIL AND BUILDING ENGINEERING, Nottinham, 2010. Proceedings... Nottinham, 2010. 


\section{Fernanda Saidelles Bataglin}

Programa de Pós-Graduação em Engenharia Civil: Construcão e Infraestrutura | Universidade Federal do Rio Grande do Sul |

Av. Osvaldo Aranha, 99, $7^{\circ}$ andar | Porto Alegre - RS - Brasil | CEP 90035-190 | Tel.: (51) 3308-4848 |

E-mail: fernanda.saidelles@gmail.com

\section{Daniela Dietz Viana}

Departamento Interdisciplinar | Universidade Federal do Rio Grande do Sul | RS 30, Km 92, Campus Litoral Norte | Tramandaí - RS - Brasil | CEP 95590-000 | Tel.: (51) 3308-1332 | E-mail: danidietz@gmail.com

\section{Carlos Torres Formoso}

Programa de Pós-Graduação em Engenharia Civil: Construção e Infraestrutura | Universidade Federal do Rio Grande do Sul |

E-mail: formoso@ufrgs.br

\section{lamara Rossi Bulhões}

Departamento Interdisciplinar | Universidade Federal do Rio Grande do Sul | Tel.: (51) 3308-1330 | E-mail: iamara.bulhoes@ufrgs.br

\section{Revista Ambiente Construído}

Associação Nacional de Tecnologia do Ambiente Construído

Av. Osvaldo Aranha, $99-3^{\circ}$ andar, Centro

Porto Alegre - RS - Brasil

$$
\text { CEP } 90035-190
$$

Telefone: +55 (51) 3308-4084

Fax: +55 (51) 3308-4054

www.seer.ufrgs.br/ambienteconstruido

E-mail: ambienteconstruido@ufrgs.br 